\title{
In vitro phase I metabolism of three phenethylamines 25D-NBOMe, 25E-NBOMe and 25N-NBOMe using microsomal and microbial models
}

Katharina Elisabeth Grafinger ${ }^{1,2}$, Katja Stahl ${ }^{3}$, Andreas Wilke ${ }^{3}$, Stefan König ${ }^{1}$, Wolfgang Weinmann ${ }^{1}$

${ }^{1}$ Institute of Forensic Medicine, Forensic Toxicology and Chemistry, University of Bern, Bühlstrasse 20, 3012 Bern, Switzerland

${ }^{2}$ Graduate School for Cellular and Biomedical Sciences, University of Bern, Freiestrasse 1, 3012 Bern, Switzerland

${ }^{3}$ Department of Mechanical and Process Engineering, University of Applied Sciences Offenburg, Badstrasse 24, 77652 Offenburg, Germany

*corresponding author: Katharina Elisabeth Grafinger, Katharina.grafinger@irm.unibe.ch Institute of Forensic Medicine, Bühlstrasse 20, 3012 Bern, Switzerland

Metabolism; NBOMe; NPS; pHLM; fungi Cunninghamella elegans; metabolism

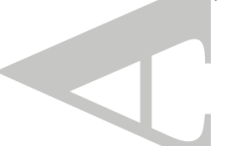

\section{Abstract:}

Numerous 2,5-dimethoxy- $N$-benzylphenethylamines (NBOMe), carrying a variety of lipophilic substituents at the 4-position, are potent agonists at 5-hydroxytryptamine $\left(5 \mathrm{HT}_{2 \mathrm{~A}}\right)$ receptors and show hallucinogenic effects. The present study investigated the metabolism of 25D-NBOMe, 25ENBOMe and 25N-NBOMe using the microsomal model of pooled human liver microsomes (pHLM) and the microbial model of the fungi Cunninghamella elegans (C. elegans). Identification of metabolites was performed using liquid chromatography-high resolution-tandem mass spectrometry (LC-HR-MS/MS) with a QqToF instrument. In total, 36 25D-NBOMe phase I metabolites, 26 25ENBOMe phase I metabolites and $2425 \mathrm{~N}-\mathrm{NBOMe}$ phase I metabolites were detected and identified in pHLM. Furthermore, 14 metabolites of 25D-NBOMe, eleven 25E-NBOMe metabolites and nine 25NNBOMe metabolites could be found in $C$. elegans. The main biotransformation steps observed were oxidative deamination, oxidative $\mathrm{N}$-dealkylation also in combination with hydroxylation, oxidative $\mathrm{O}$ demethylation possibly combined with hydroxylation, oxidation of secondary alcohols, mono- and dihydroxylation, oxidation of primary alcohols and carboxylation of primary alcohols. Additionally, oxidative di-O-demethylation for 25E-NBOMe and reduction of the aromatic nitro group and $\mathrm{N}$ acetylation of the primary aromatic amine for $25 \mathrm{~N}-\mathrm{NBOMe}$ took place. The resulting $25 \mathrm{~N}-\mathrm{NBOMe}$ metabolites were unique for NBOMe compounds. For all NBOMes investigated, the corresponding 2,5-dimethoxyphenethylamine (2C-X) metabolite was detected. This study reports for the first time 25X-NBOMe $N$-oxide metabolites and hydroxylamine metabolites, which were identified for 25DNBOMe and 25N-NBOMe and all three investigated NBOMes, respectively. C. elegans was capable of generating all main biotransformation steps observed in pHLM and might therefore be an interesting model for further studies of new psychoactive substances (NPS) metabolism.

This article has been accepted for publication and undergone full peer review but has not been through the copyediting, typesetting, pagination and proofreading process which may lead to differences between this version and the Version of Record. Please cite this article as doi: $10.1002 /$ dta.2446 


\section{Introduction:}

In the last ten years, new psychoactive substances (NPS) have become a growing problem. Chatwin et al. ${ }^{1}$ define NPS as "chemical compounds that have been modified and developed to mimic the effects of drugs which are already prohibited". Currently, the European Union (EU) Early Warning System, coordinated by the European Monitoring Centre for Drugs and Drug Addiction (EMCDDA), is monitoring over 620 NPS, with one sixth of them belonging to the chemical class of phenethylamines ${ }^{2,3}$. Prominent substances belonging to this class are 2C-type phenethylamines ${ }^{4}$, which are 2,5-dimethoxyphenethylamines, substituted at the 4-position, typically with halogens or alkyl groups, and also 2,5-dimethoxy- $N$-benzylphenethylamines, so called NBOMes which have emerged in recent years ${ }^{5}$. Substitutions on the 4-position include bromine (25B-NBOMe), chlorine (25C-NBOMe), methyl (25D-NBOMe), ethyl (25E-NBOMe), iodine (25I-NBOMe), nitro (25N-NBOMe) groups but the unsubstituted form ( $25 \mathrm{H}-\mathrm{NBOMe})$ is also available ${ }^{6}$, which has been detected as an impurity in blotter papers ${ }^{7}$. These substances were found to be potent $5 \mathrm{HT}_{2 \mathrm{~A}}$ receptor agonists ${ }^{8-11}$. Furthermore, Braden et al. could show that the addition of the $\mathrm{N}$-methoxybenzyl group to $2 \mathrm{C}-\mathrm{X}$ compounds significantly increases their affinity to the $5-\mathrm{HT}_{2 \mathrm{~A}}$ receptor and therefore results in higher behavioural responses ${ }^{12}$. NBOMes and their homologues produce psycho- and cardiovascular stimulant effects in addition to hallucinations ${ }^{13}$. In cases of acute drug intoxication, sympathomimetic toxicity such as tachycardia, hypertension, mydriasis, agitation, vasoconstriction and hyperthermia were observed ${ }^{14-17}$, which could point towards serotonin syndrome. Recommended treatment in case of intoxication is heart rate, blood pressure and body temperature monitoring ${ }^{18}$. Furthermore, for acute treatment of sympathomimetic toxidrome, administration of benzodiazepines, fluid replacement and physical cooling should be performed to control agitation, cardiovascular stimulation and hyperthermia due to serotonin toxicity ${ }^{16,18,19}$. NBOMe compounds are usually taken in doses of $200 \mu \mathrm{g}$ to $2000 \mu \mathrm{g}$ (depending on the compound), mainly by sublingual application on blotter papers, and they have been reported to be sold as counterfeit LSD products ${ }^{20}$, ${ }^{21}$. Several NBOMe case studies of intoxication with non-fatal ${ }^{15,16,22}$ and fatal intoxication ${ }^{13,23,24}$ have been reported. The presence of metabolites is proof of consumption of the parent substrate. Therefore, metabolism studies are needed to identify metabolites of NPS, which can then be used as biomarkers to confirm consumption. Another issue concerning NPS is the lack of reference standards, which can be overcome by identifying unique fingerprints of drug metabolites.

In order to form phase I and phase II metabolites, different in vivo and in vitro models are available. Human studies are ethically not favourable and therefore animal in vivo studies or in vitro alternatives are commonly used. Pooled human liver microsomes ( $\mathrm{pHLM}$ ) have been shown to be a reliable in vitro model for the generation of phase I metabolites ${ }^{25-27}$. An alternative to in vitro models, such as primary human hepatocytes $(\mathrm{PHH})$, pooled human $\mathrm{S9}$ fraction (pS9) or pHLM ${ }^{28}$, are microbial models of the fungus Cunninghamella elegans (C. elegans). Microbial models have the advantage of low cost, easy handling, scale-up capability and further to reduce use of animals ${ }^{29}$. Moreover, C. elegans has the enzymatic activity of both phase I and II enzymes ${ }^{29}$ and holds the cytochrome P450 CYP509A1 enzyme ${ }^{30}$. This class of fungi has the ability to facilitate reactions such as hydroxylation, carboxylation, dihydrodiol formation, oxidative defluorination, $\mathrm{N}$-dealkylation, glucuronidation and sulfation ${ }^{31,32}$, as well as those catalysed by human CYP1A2, CYP2C9, CYP2C19, CYP2D6 and CYP3A4 ${ }^{29,32-34}$. It was recently shown by Nielsen et al. ${ }^{35}$ that the main enzymes involved in the 25I-NBOMe metabolism are CYP3A4 and CYP2D6. Caspar et al. ${ }^{4}$ reported that for 25B-NBOMe and 25C-NBOMe the enzymes CYP1A2, CYP3A4, CYP2C9 and CYP2C19 play a crucial role.

This article is protected by copyright. All rights reserved. 
The aim of the present study was to conduct metabolism studies of three different NBOMe analogues, 25D-NBOMe, 25E-NBOMe and 25N-NBOMe employing pHLM and C. elegans and to identify phase I metabolites based on mass spectrometric data. Besides the most common analogues 25B-NBOMe and 25I-NBOMe, the three analogues have previously been identified on confiscated blotter papers ${ }^{7}$. All measurements were performed using liquid chromatography-high resolution-tandem mass spectrometry (LC-HR-MS/MS) and metabolites were identified according to their precursor masses, the most abundant product ions and the isotope patterns. So far no biotransformation data are available on the three investigated NBOMes.

\section{Materials and Methods}

\subsection{Chemicals and Reagents}

Yeast extract, malt extract and peptone from soy beans were obtained from Carl Roth (Karlsruhe, Germany), glucose from Applichem (Darmstadt, Germany). C. elegans strain DMSZ 1908 was obtained from Leibniz Institute DSMZ-German Collection of Microorganisms and Cell Cultures (Braunschweig, Germany). Sodium hydroxide, magnesium chloride and disodiumhydrogenphosphate-dihydrate were purchased from Merck AG (Zug, Switzerland), sulfosalicylic acid and superoxide dismutase (6016 units/mg protein) from Sigma Aldrich (Buchs, Switzerland). Pooled human S9 fraction (pS9) (150 donors, $20 \mathrm{mg} / \mathrm{mL}$ ), pooled human liver microsomes (pHLM) (150 donors, $20 \mathrm{mg} / \mathrm{mL}$ ), NADPH-regenerating solutions A/B , UGT-reaction mix $\mathrm{A} / \mathrm{B}$ and $0.5 \mathrm{M}$ potassium phosphate buffer $\mathrm{pH} 7.4$ were obtained from Corning (New York, NY, USA). Hydrochloride salts of 25D-NBOMe (98.5\%), 25E-NBOMe (>98.5\%), and 25N-NBOMe (98.5\%), were purchased from Lipomed (Arlesheim, Switzerland). The reference standard of 25B-NBOMe-D $\mathrm{D}_{3}(0.01$ $\mathrm{mg} / \mathrm{mL}$ in methanol) was obtained from Cerilliant (Round Rock, TX, USA). Formic acid (analytical grade, $98 \%$ ) and ammonium formate were obtained from Fluka (Sigma-Aldrich, Buchs, Switzerland), methanol (absolute, HPLC grade) from Biosolve (Chemie Brunschwig, Basel, Switzerland), acetonitrile (HPLC gradient grade, $99.9 \%$ ) and 1-chlorobutane (HPLC gradient grade, $99.8 \%$ ) from Acros Organics (Chemie Brunschwig, Basel, Switzerland). Direct-Q water purification system from Millipore (Zug, Switzerland) was used to produce in-house ultrapure water. All solutions and samples were handled using precision pipettes from Gilson (Mettmenstetten, Switzerland) and Socorex Isba S.A (Ecublens, Switzerland)

\subsection{In Silico predictions}

Prediction of possible metabolites was carried out in order to assist in the interpretation of the collected mass spectrometric data, using Meteor Nexus v.3.0.1 (Lhasa Limited). It is a knowledgebased expert system that predicts the biotransformation of a substrate ${ }^{36}$. Parameters were as follows: species human, processing direction breath first, maximal depth 3, absolute reasoning: minimum likelihood equivocal and relative reasoning: level of cut-off 2 . Results of the in silico predictions were compared to information independent LC-HR-MS/MS measurements using the Analyst software 1.6 TF with MasterView ${ }^{\mathrm{TM}}$ Software Version 1.1 with the extracted ion current (XIC) tool.

\subsection{Microsomal assay using pHLM}

For generating phase I metabolites, microsomal in vitro experiments were performed as previously published ${ }^{27}$. Briefly, the following components were mixed in a reaction tube, with a final volume of 
$50 \mu \mathrm{L}$ and indicated concentrations are final concentrations: deionized water, potassium phosphate buffer $(100 \mathrm{mM})$, magnesium chloride $(5 \mathrm{mM})$, superoxide dismutase (200 units $/ \mathrm{mL}), \mathrm{NADPH}-$ regenerating solution A (NADP+ and glucose-6-phosphate) and B (glucose-6-phosphate dehydrogenase), pHLM (1 mg/mL) and a reference standard of one of the three investigated NBOMes $(25 \mu \mathrm{M})$. Samples were incubated for $60 \mathrm{~min}$ at $37{ }^{\circ} \mathrm{C}$, which is an commonly reported incubation time in literature. Simultaneously, blanks containing no drug substrates and negative controls containing no pHLM were prepared. The reactions were stopped by adding $50 \mu \mathrm{L}$ ice cold acetonitrile containing an internal standard of 25B-NBOMe- $\mathrm{D}_{3}$. After mixing, the samples were centrifuged at $17^{\prime} 000 \mathrm{~g}$ and $8{ }^{\circ} \mathrm{C}$ for $10 \mathrm{~min}$ and the supernatants transferred to autosampler vials. The samples were evaporated to dryness at $50{ }^{\circ} \mathrm{C}$ under nitrogen and reconstituted in $50 \mu \mathrm{L}$ water/acetonitrile/formic acid, (95:5:0.1; v/v/v). Experiments were conducted in triplicates.

\subsection{Microbial assay using fungi $C$. elegans}

The growth medium was prepared according to the DSMZ Medium 186 (Leibniz Institute DSMZ German Collection of Microorganisms and Cell Cultures) ${ }^{37}$. The media components containing yeast extract $(3 \mathrm{~g} / \mathrm{L})$, malt extract $(3 \mathrm{~g} / \mathrm{L}$ ) and peptone from soy beans $(5 \mathrm{~g} / \mathrm{L})$ (solution A, without agar) and glucose $(10 \mathrm{~g} / \mathrm{L}$ ) (solution $\mathrm{B}$ ) were dissolved separately in deionized water. After autoclaving both solutions were mixed. For the cultivation of $C$. elegans, the medium $(30 \mathrm{~mL})$ was inoculated with a piece of mycelium from the agar plate. The culture flasks were shaken for three days at $100 \mathrm{rpm}$ at $28^{\circ} \mathrm{C}$ on a rotary shaker (KS 260 basic, IKA-Werke GmbH \& Co. Kg, Staufen im Breisgau, Germany). On day three, the $C$. elegans biomasses were transferred to new flasks containing fresh medium and were again inoculated with a piece of mycelium. This way, two different growth stadiums of the fungi biomasses were obtained, which increased the ability of the fungi to metabolise. Solutions of each NBOMe were prepared in $70 \%$ ethanol with concentrations of $50 \mu \mathrm{M}$. On day four, $800 \mu \mathrm{L}$ of NBOMe solution was added to the culture flask and incubated for 72 hours by shaking at $100 \mathrm{rpm}$ at $28^{\circ} \mathrm{C}$. In preliminary experiments, the incubation time was evaluated for time points $24,48,72$ and 96 hours. Results showed that 72 and 96 hours of incubation resulted equally in the most amount of metabolites, therefore 72 hours were chosen as incubation time. After three days, the reaction was stopped and the growth medium and the fungi biomass stored separately in $30 \mathrm{~mL}$ falcon tubes at $20{ }^{\circ} \mathrm{C}$, this stops the fungi's ability to further metabolise. Samples were stored at $-20^{\circ} \mathrm{C}$ until they were processed. Experiments were carried out in duplicates. In preliminary experiments, the growth medium has been analysed but only the parent compounds were detected. The reason for this is that the fungi only takes up the substrates in the growth medium but does not release the formed metabolites back to it. Therefore, for the detection and identification of metabolites in the fungi biomass was intensively analysed. Additionally, this made it necessary to homogenize the fungi biomass.

Extractions were performed as follows: on average, $1.10 \mathrm{~g}$ (range 1.03-1.15 g) fungi biomass were weighed into a homogenization tube (gentleMacs M Tubes, Macs Miltenyi Biotec, Bergisch Gladbach, Germany), and $4 \mathrm{~mL}$ of phosphate puffer $\mathrm{pH} 9$ added. The fungi sample was homogenized with a gentle Macs Dissociator, using a pre-programmed gradient of 45 seconds. One $\mathrm{mL}$ of the fungi solution was then transferred to a new vial and $10 \mu \mathrm{L}$ internal standard 25B-NBOMe- $\mathrm{D}_{3}(2000 \mathrm{ng} / \mathrm{mL})$ and $1.5 \mathrm{~mL} 1$-chlorobutane added. Afterwards, the sample was mixed for at least $10 \mathrm{~min}$ followed by centrifugation for $10 \mathrm{~min}$ at $17^{\prime} 000 \mathrm{~g} \mathrm{rpm}$ at $8^{\circ} \mathrm{C}$. The supernatant was then transferred to an 
autosampler vial and evaporated under nitrogen at $50{ }^{\circ} \mathrm{C}$. Finally, the sample was reconstituted in $100 \mu \mathrm{L}$ water/acetonitrile/formic acid (95:5:0.1; v/v/v).

\subsection{LC-HR-MS/MS analysis}

All samples were analysed using a Dionex Ultimate 3000 HPLC system (Thermo Fisher Scientific, Reinach, Switzerland) coupled to a 5600 TripleTof System equipped with a DuoSpray interface and Analyst software 1.6 TF with MasterView ${ }^{\mathrm{TM}}$ Software Version 1.1 (Sciex, Toronto, Canada). For data evaluation, the following parameters were chosen: a cut-off mass error of $5 \mathrm{ppm}$, intensities higher than $500 \mathrm{cps}$ and only peaks eluting in the gradient within 2 and $22 \mathrm{~min}$. Chromatographic separation was performed on a reversed phase Kinetex $C 8$ column, $2.6 \mu \mathrm{m}, 100 \AA, 100 \times 2.1 \mathrm{~mm}$ (Phenomenex, Basel, Switzerland). The mobile phase consisted of water with $0.1 \%$ formic acid (A) and acetonitrile with $0.1 \%$ formic acid (B) with a flow rate of $0.25 \mathrm{~mL} / \mathrm{min}$. The following gradient was applied: 0-1 min: $2.5 \%$ B, 1-20 min: $2.5 \%$ to $40 \%$ B, 20-24 min: 40-97.5 \% B, 24-28 min: $97.5 \%$ B, 28- $30 \mathrm{~min}: 97.5-2.5 \% \mathrm{~B}$ and 30-35 min: $2.5 \% \mathrm{~B}$. The injection volume was $1.0 \mu \mathrm{L}$. The MS parameters were as follows: ESI voltage $5.0 \mathrm{kV}$, source temperature $650{ }^{\circ} \mathrm{C}$, curtain gas 55 arbitrary units, gas 1 and 2 at 55 arbitrary units. All data were acquired in positive ion mode. Information dependent data acquisition (IDA) was carried out using a survey scan from $\mathrm{m} / \mathrm{z} 100$ to 950 , triggering the acquisition of product ion mass spectra for the nine most abundant precursor ions in a mass range from $\mathrm{m} / \mathrm{z} 50$ to 950 . For dependent and survey scans the accumulation time was set to $40 \mathrm{~ms}$ and $50 \mathrm{~ms}$, respectively. The collision energy was set to $35 \mathrm{eV}$ and a collision energy spread of \pm 15 eV. The SCIEX QqToF system used is automatically calibrated at the start of every new chromatogram by injection of a calibration solution directly in the ion source (post-column).

\section{Results and Discussion}

In order to exclude matrix peaks as potential metabolites, all data obtained were compared to blank pHLM and fungi samples, containing the matrix but no drug and negative control samples containing no pHLM, respectively. The in silico predictions obtained from Meteor Nexus v.3.0.1 software assisted in the analysis of obtained IDA LC-HR-MS/MS scans. Extracted ion chromatograms of each 25X-NBOMe and their metabolites are presented in Figures 1 to 3 , with the upper chromatogram (A) belonging to the pHLM sample and the lower one (B) to the fungi $C$. elegans sample. The proposed biotransformation pathways for each compound are displayed in Figure 4 to 6 . Metabolites labelled with $(F)$ were present in both pHLM and $C$. elegans. Detailed lists of all identified metabolites are displayed in Tables 1 to 3.

\subsection{Identification of metabolites}

The molecular structure of 25X-NBOMe compounds and metabolites can be divided into two parts: the 4-substituted 2,5-dimethoxyphenethylamine is referred as the $2 \mathrm{C}$ part and the $\mathrm{N}-(2-$ methoxybenzyl) is the so called NBOMe part ${ }^{4}$. Figure 7 presents the nomenclature used for the description of fragmentation and positions of metabolisation. A large number of metabolites was identified for each 25X-NBOMe and therefore only the characteristic product ions used for identification will be discussed in detail. Representative product ion mass spectra of metabolites for each 25X-NBOMe are displayed in Figure 8. All other mass spectra can be found in the supporting information. The parent compounds and their metabolites were identified by precursor ion masses of the respective protonated molecule, their most abundant product ions and isotope pattern, and 
for those metabolites occurring in both $\mathrm{pHLM}$ and the fungi $C$. elegans, by their retention times. The protonated masses and product ions given are the calculated values.

For the 25X-NBOMe parent compounds, the respective precursor ions and the product ions with $\mathrm{m} / \mathrm{z}$ 121.0653 and $\mathrm{m} / \mathrm{z} 91.5048$ (representing the NBOMe part) were present. The product ions resulted due to amine cleavage of the NBOMe moiety forming $\left[\mathrm{C}_{8} \mathrm{H}_{9} \mathrm{O}\right]^{+}(\mathrm{m} / \mathrm{z} 121.0653)$ and further demethoxylation via neutral loss of formaldehyde forming the tropylium ion $\left[\mathrm{C}_{7} \mathrm{H}_{7}\right]^{+}\left(\mathrm{m} / 2 \mathrm{~g}\right.$ 91.0548) ${ }^{38}$. These product ions were consistent with previously published data on 25B-NBOMe, 25C-NBOMe and 25I-NBOMe, because the alterations between the 25X-NBOMe are on the $2 \mathrm{C}$ part at the 4-position ${ }^{4}$, 6, 39. The following observations can be made for all metabolites of 25X-NBOMe substances: If product ions with $\mathrm{m} / \mathrm{z} 121.0653$ and $\mathrm{m} / \mathrm{z} 91.0534$ are present, no biotransformation occurs at the NBOMe part. A product ion with $\mathrm{m} / z 107.0497$ is characteristic for oxidative $O$-demethylation at the 2-position at the NBOMe part forming an hydroxy-cycloheptatrienylium $\left(\left[\mathrm{C}_{7} \mathrm{H}_{7} \mathrm{O}\right]^{+}\right)$. A product ion with $\mathrm{m} / \mathrm{z} \quad 123.0446\left(\left[\mathrm{C}_{7} \mathrm{H}_{7} \mathrm{O}_{2}\right]^{+}\right)$indicates that simultaneous oxidative $O$-demethylation and hydroxylation occurred on the NBOMe part. Hydroxylation on the NBOMe ring led to the product ions with $\mathrm{m} / \mathrm{z} 137.0603\left(\left[\mathrm{C}_{8} \mathrm{H}_{9} \mathrm{O}_{2}\right]^{+}\right)$in combination with a product ion with either $\mathrm{m} / \mathrm{z} 107.0497$ $\left(\left[\mathrm{C}_{7} \mathrm{H}_{7} \mathrm{O}\right]^{+}\right)$or $m / z 123.0446\left(\left[\mathrm{C}_{7} \mathrm{H}_{7} \mathrm{O}_{2}\right]^{+}\right)$. Dihydroxylation at the NBOMe part resulted in a product ion with $\mathrm{m} / \mathrm{z} 153.0552\left(\left[\mathrm{C}_{8} \mathrm{H}_{9} \mathrm{O}_{3}\right]^{+}\right)$. . All other product ions were specific to the $2 \mathrm{C}$ part and are discussed in the following paragraphs.

\subsubsection{D-NBOMe}

Thirty-six distinctive 25D-NBOMe metabolites were identified in pHLM and 14 in fungi $C$. elegans. The fragmentation of the parent compound 25D-NBOMe $\left(\mathrm{C}_{19} \mathrm{H}_{25} \mathrm{NO}_{3}\right.$ precursor ion $[\mathrm{M}+\mathrm{H}]^{+} \mathrm{m} / \mathrm{z}$ 316.1907) resulted in product ions with $\mathrm{m} / \mathrm{z}$ 179.1072, $\mathrm{m} / \mathrm{z} 121.0653, \mathrm{~m} / \mathrm{z} 91.0538$ and the protonated molecule with $\mathrm{m} / \mathrm{z} 316.1900$. This product ion represented amine cleavage forming $\left[\mathrm{C}_{11} \mathrm{H}_{15} \mathrm{O}_{2}\right]^{+}$, and the last two are specific for the intact NBOMe part. These product ions can be used among others for identifying metabolites in combination with previously mentioned product ions. When a product ion with $m / z 179.1072\left(\left[\mathrm{C}_{11} \mathrm{H}_{15} \mathrm{O}_{2}\right]^{+}\right)$was present no biotransformation took place on the $2 \mathrm{C}$ part but was possible on the amine. An intact 2,5-dimethoxy-1,4-dimethyl cation was identified with a product ion with $\mathrm{m} / \mathrm{z} 165.0916\left(\left[\mathrm{C}_{10} \mathrm{H}_{13} \mathrm{O}_{2}\right]^{+}\right)$. The three $\mathrm{O}$-demethylated metabolites (D7-D9: $\mathrm{C}_{18} \mathrm{H}_{23} \mathrm{NO}_{3}$ precursor ion $[\mathrm{M}+\mathrm{H}]^{+} \mathrm{m} / z$ 302.1751) were differentiated depending on following product ions (besides the precursor ions and product ions): the occurrence of the product ions $\mathrm{m} / \mathrm{z}$ 121.0653 and $\mathrm{m} / \mathrm{z} 91.0548$ characteristic for the NBOMe part means that $O$-demethylation occurs on the $2 \mathrm{C}$ part, and a product ion of $\mathrm{m} / z 107.0497\left(\left[\mathrm{C}_{7} \mathrm{H}_{7} \mathrm{O}\right]^{+}\right)$means that $\mathrm{O}$-demethylation takes place on the NBOMe moiety. The mono-hydroxylated in combination with O-demethylated metabolites (D10-D19: $\mathrm{C}_{18} \mathrm{H}_{23} \mathrm{NO}_{4}$ precursor ion $[\mathrm{M}+\mathrm{H}]^{+} \mathrm{m} / \mathrm{z}$ 318.1700) were identified as follows: The mass spectrum of metabolite D10 only displays two product ions which are typical for an intact NBOMe part. Therefore, the only statement that can be made is that both $O$-demethylation and hydroxylation occur on the $2 \mathrm{C}$ part. Due to the lack of fragmentation and since tertiary hydrocarbons are preferred over secondary hydrocarbons as site of hydroxylation, it is more likely that hydroxylation occurs on the 2,5-dimethoxy-4-dimethyl ${ }^{40}$. The fragmentation of D11 displays the loss of a water molecule from the precursor ion forming $\mathrm{m} / \mathrm{z} 300.1600\left(\left[\mathrm{C}_{18} \mathrm{H}_{22} \mathrm{NO}_{3}\right]^{+}\right)$, which correlates with a rearrangement forming a double bound. Furthermore, the two characteristic NBOMe part product ions are present, which indicate that biotransformation must have occurred on the $2 \mathrm{C}$ part. For metabolite D12, the position of hydroxylation was narrowed down to $\alpha$ position or the amine

This article is protected by copyright. All rights reserved. 
forming a hydroxylamine because the product ion of $m / z 151.0759\left(\left[\mathrm{C}_{9} \mathrm{H}_{11} \mathrm{O}_{2}\right]^{+}\right)$correlates with an $\alpha$ cleavage. The metabolite D14 has a very interesting combination of product ions, which would singularly point into other directions but in their combination only one structure is possible. The typical NBOMe part product ions are not present, which means that either $O$-demethylation or hydroxylation occurred on this part. Both, $O$-demethylation and hydroxylation on the NBOMe part is not possible because then a product ion with $\mathrm{m} / z 123.0446\left(\left[\mathrm{C}_{7} \mathrm{H}_{7} \mathrm{O}_{2}\right]^{+}\right)$would be observed. The product ion with $m / z 137.0603\left(\left[\mathrm{C}_{8} \mathrm{H}_{9} \mathrm{O}_{2}\right]^{+}\right)$in combination with $m / z 165.0916\left(\left[\mathrm{C}_{10} \mathrm{H}_{13} \mathrm{O}_{2}\right]^{+}\right)$result from $\mathrm{O}$-demethylation on the $2 \mathrm{C}$ part and are formed due to $\beta$-cleavage and amine cleavage, respectively. The product ion of $m / z 107.0497\left(\left[\mathrm{C}_{7} \mathrm{H}_{7} \mathrm{O}\right]^{+}\right)$is formed by $\alpha^{\prime}$-cleavage of the NBOMe part. For metabolite D15, the site of hydroxylation could only be narrowed down to $\alpha$ or $\beta$ position. As described for D14, the product ion with $m / z 123.0446\left(\left[\mathrm{C}_{7} \mathrm{H}_{7} \mathrm{O}_{2}\right]^{+}\right)$can only occur when $O$ demethylation and hydroxylation are occurring combined on the NBOMe part. The product ion with $\mathrm{m} / \mathrm{z} 179.1072\left(\left[\mathrm{C}_{11} \mathrm{H}_{15} \mathrm{O}_{2}\right]^{+}\right)$results from amine cleavage and occurs from an intact $2 \mathrm{C}$ part. The hydroxylation is narrowed down to vicinal position. For the identification of the site of monohydroxylation, several specific product ions were used (D21-D25: $\mathrm{C}_{19} \mathrm{H}_{25} \mathrm{NO}_{4}$ precursor ion $[\mathrm{M}+\mathrm{H}]^{+}$ $\mathrm{m} / \mathrm{z} 332.1856$ ). Firstly, an intact 2,5-dimethoxy-4-methylphenyl moiety (therefore hydroxylation not taking place on this site) correlated with a product ion with $\mathrm{m} / z 180.1025\left(\left[\mathrm{C}_{10} \mathrm{H}_{14} \mathrm{NO}_{2}\right]^{+}\right)$. Secondly, hydroxylation occurring on the $2 \mathrm{C}$ part resulted in a product ion with $\mathrm{m} / \mathrm{z} 210.1130\left(\left[\mathrm{C}_{11} \mathrm{H}_{16} \mathrm{NO}_{3}\right]^{+}\right)$, which could be further narrowed down with a product ion with $m / z 195.1010\left(\left[\mathrm{C}_{11} \mathrm{H}_{15} \mathrm{O}_{3}\right]^{+}\right)$, which in turn specified that hydroxylation took place on the $2 \mathrm{C}$ part but not on the amine. The exact site of hydroxylation is discussed more in detail as follows: For D22, the product ion with $\mathrm{m} / \mathrm{z} 165.0916$ $\left(\left[\mathrm{C}_{10} \mathrm{H}_{13} \mathrm{O}_{2}\right]^{+}\right)$is formed due to $\alpha$-cleavage, the product ion $\mathrm{m} / z \mathrm{z} 195.1021\left(\left[\mathrm{C}_{11} \mathrm{H}_{15} \mathrm{O}_{3}\right]^{+}\right)$is formed due to amine cleavage. On the basis of these two fragments and the typical NBOMe part fragment the site of hydroxylation can only be the $\alpha$ position. D23 and D25 have the same mass spectra. The two product ions with $m / z 195.1021\left(\left[\mathrm{C}_{11} \mathrm{H}_{15} \mathrm{O}_{3}\right]^{+}\right), \mathrm{m} / z$ 180.1025 $\left(\left[\mathrm{C}_{10} \mathrm{H}_{14} \mathrm{NO}_{2}\right]^{+}\right)$and the two NBOMe part ions are formed due to $\alpha$-cleavage and amine cleavage, respectively. Based on these two fragments, it can be concluded that hydroxylation occurs in $\alpha$ or $\beta$ position. For metabolite D24, the position of the hydroxylation can be narrowed down to the vicinal position due to following fragments: The presence of the product ions with $\mathrm{m} / \mathrm{z} 179.1072\left(\left[\mathrm{C}_{11} \mathrm{H}_{15} \mathrm{O}_{2}\right]^{+}\right)$means that no biotransformation occurs on the $2 \mathrm{C}$ part, it is formed due to amine cleavage. The absence of the typical NBOMe part product ions let conclude that hydroxylation must occur on this part. And finally, the product ions with $m / z 137.0603\left(\left[\mathrm{C}_{8} \mathrm{H}_{8} \mathrm{O}_{2}\right]^{+}\right)$and $m / z 107.0497\left(\left[\mathrm{C}_{7} \mathrm{H}_{7} \mathrm{O}\right]^{+}\right)$narrow down the site of hydroxylation to vicinal position because they are formed by dealkylation and $\alpha^{\prime}$-cleavage, respectively. The $\mathrm{N}$-oxide metabolite D27 is eluting $0.91 \mathrm{~min}$ after the parent substrate, which is typical for $\mathrm{N}$-oxides on reversed phase columns ${ }^{41}$, and the product ions of $m / z 179.1072\left(\left[\mathrm{C}_{11} \mathrm{H}_{15} \mathrm{O}_{2}\right]^{+}\right)$(formed by amine cleavage) and the two NBOMe ions lead to the only conclusion, that it is an $\mathrm{N}$-oxide. D29 is identified as follows: the product ion with $\mathrm{m} / z 151.0759\left(\left[\mathrm{C}_{9} \mathrm{H}_{11} \mathrm{O}_{2}\right]^{+}\right)$correlates with an intact 2,5-dimethoxy-4methylphenyl moiety and is formed by $\beta$-cleavage. Using the two product ions with $\mathrm{m} / \mathrm{z} 195.1021$ $\left(\left[\mathrm{C}_{11} \mathrm{H}_{15} \mathrm{O}_{3}\right]^{+}\right)$and $m / z 135.0446\left(\left[\mathrm{C}_{8} \mathrm{H}_{7} \mathrm{O}_{2}\right]^{+}\right.$) (formed by amine cleavage and dealkylation), the sites of hydroxylation and oxidation of alcohols can be narrowed down to $\alpha$ - and vicinal position. The fragmentation of D30 resulted in $m / z 165.0916\left(\left[\mathrm{C}_{10} \mathrm{H}_{13} \mathrm{O}_{2}\right]^{+}\right), \mathrm{m} / z 137.0603\left(\left[\mathrm{C}_{8} \mathrm{H}_{8} \mathrm{O}_{2}\right]^{+}\right)$and $\mathrm{m} / \mathrm{z}$ $107.0497\left(\left[\mathrm{C}_{7} \mathrm{H}_{7} \mathrm{O}\right]^{+}\right)$, resulting from $\alpha$-cleavage, dealkylation and $\alpha^{\prime}$-cleavage, respectively. Using these product ions the sites of hydroxylation are $\alpha$ and vicinal position. Metabolites D35 and D36 have identical mass spectra. Using the product ions $m / z 179.1072\left(\left[\mathrm{C}_{11} \mathrm{H}_{15} \mathrm{O}_{2}\right]^{+}\right)$and $\mathrm{m} / z 153.0552$ $\left(\left[\mathrm{C}_{8} \mathrm{H}_{9} \mathrm{O}_{3}\right]^{+}\right)$, which are formed by amine cleavage and dealkylation, it can be concluded that both 
hydroxylations must occur on the NBOMe part. Furthermore, the product ion $\mathrm{m} / \mathrm{z} 123.0446$ $\left(\left[\mathrm{C}_{7} \mathrm{H}_{7} \mathrm{O}_{2}\right]^{+}\right)$, formed by $\alpha^{\prime}$-cleavage, determines that one hydroxylation takes place in vicinal position and the other one on the NBOMe ring.

\subsubsection{E-NBOMe}

For 25E-NBOMe, 26 distinctive metabolites were identified in pHLM and 11 in the fungi $C$. elegans. The fragmentation of $25 \mathrm{E}-\mathrm{NBOMe}$ (precursor ion $[\mathrm{M}+\mathrm{H}]^{+} \mathrm{m} / \mathrm{z} 329.1991$ ) resulted in product ions with $\mathrm{m} / \mathrm{z}$ 193.1222, $\mathrm{m} / \mathrm{z} 121.0653$ and $\mathrm{m} / \mathrm{z}$ 91.0534. These product ions correlated with amine cleavage of the $2 \mathrm{C}$ part forming $\left[\mathrm{C}_{12} \mathrm{H}_{17} \mathrm{O}_{2}\right]^{+}$, and further the two specific NBOMe part product ions. Again, this first product ion with $\mathrm{m} / \mathrm{z} 193.1229\left(\left[\mathrm{C}_{12} \mathrm{H}_{17} \mathrm{O}_{2}\right]^{+}\right)$represented an intact $2 \mathrm{C}$ part (independent of biotransformation on the amine). When hydroxylation took place on the $2 \mathrm{C}$ part a product ion with $\mathrm{m} / \mathrm{z} 209.1178\left(\left[\mathrm{C}_{12} \mathrm{H}_{17} \mathrm{O}_{3}\right]^{+}\right)$was observed. When a product ion with $\mathrm{m} / \mathrm{z} 181.0865$ $\left(\left[\mathrm{C}_{10} \mathrm{H}_{13} \mathrm{O}_{3}\right]^{+}\right)$was found, simultaneous double oxidative $\mathrm{O}$-demethylation and hydroxylation on the $2 \mathrm{C}$ part occurred. For the two identified di-O-demethylated metabolites E5 and E6 $\left(\mathrm{C}_{18} \mathrm{H}_{23} \mathrm{NO}_{3}\right.$, precursor ion $[\mathrm{M}+\mathrm{H}]^{+} \mathrm{m} / \mathrm{z}$ 302.1751), three different sites of $\mathrm{O}$-demethylation are possible. This could be narrowed down by the presence (E6) or absence (E5) of the two typical NBOMe part product ions $m / z 121.0653$ and $m / z 91.0534$ or the product ion $m / z 107.0497\left(\left[\mathrm{C}_{7} \mathrm{H}_{7} \mathrm{O}\right]^{+}\right)$that correlates with $O$-demethylation occurring on the NBOMe part. The mono-O-demethylation can occur on three different sites (E7-E9: $\mathrm{C}_{19} \mathrm{H}_{25} \mathrm{NO}_{3}$, precursor ion $[\mathrm{M}+\mathrm{H}]^{+} \mathrm{m} / z$ 316.1907). E7 and $\mathrm{E} 8$ had the same mass spectra, with the product ions $m / z 179.1072\left(\left[\mathrm{C}_{11} \mathrm{H}_{15} \mathrm{O}_{2}\right]^{+}\right), \mathrm{m} / z 121.0653$ and $\mathrm{m} / \mathrm{z}$ 91.0534. These correlate with amine cleavage and the two typical NBOMe part fragments,

respectively. E9 fragmented among others into the product ions $m / z 107.0497\left(\left[\mathrm{C}_{7} \mathrm{H}_{7} \mathrm{O}\right]^{+}\right)$, which stands for $O$-demethylation occurring on the NBOMe part and $m / z \quad 193.1229\left(\left[\mathrm{C}_{12} \mathrm{H}_{17} \mathrm{O}_{2}\right]^{+}\right)$ representing an intact $2 \mathrm{C}$ part. Metabolites E10 and E11 with di-O-demethylation and simultaneous hydroxylation $\left(\mathrm{C}_{18} \mathrm{H}_{23} \mathrm{NO}_{4}\right.$ precursor ion $[\mathrm{M}+\mathrm{H}]^{+} \mathrm{m} / z$ 318.1700) displayed similar fragmentation with the product ions $\mathrm{m} / \mathrm{z} 181.0865\left(\left[\mathrm{C}_{10} \mathrm{H}_{13} \mathrm{O}_{3}\right]^{+}\right)$and $\mathrm{m} / \mathrm{z} 121.0653$ and $\mathrm{m} / \mathrm{z} 91.0534$, correlating with amine cleavage and the NBOMe part product ions. Hence, both di-O-demethylation and hydroxylation must occur on the $2 \mathrm{C}$ part. Eight different mono-O-demethylated and hydroxylated metabolites were detected (E12-E19: $\mathrm{C}_{19} \mathrm{H}_{25} \mathrm{NO}_{4}$, precursor ion $[\mathrm{M}+\mathrm{H}]^{+} m / z 332.1856$ ). For metabolite E18 no mass spectrum was triggered, therefore no statement on its structure can be made. The sites of $O$-demethylation and hydroxylation were differentiated as follows: $\mathrm{E} 14$ and E19 display the same product ions with $m / z 179.1072\left(\left[\mathrm{C}_{11} \mathrm{H}_{15} \mathrm{O}_{2}\right]^{+}\right), \mathrm{m} / z 165.0916\left(\left[\mathrm{C}_{10} \mathrm{H}_{13} \mathrm{O}_{2}\right]^{+}\right), \mathrm{m} / \mathrm{z} 121.0653$ and $\mathrm{m} / \mathrm{z}$ 91.0534, which are formed by amine cleavage, $\alpha$-cleavage and the two typical NBOMe part fragments, respectively. Due to these product ions hydroxylation can only occur on the amine forming hydroxylamine metabolites. The mass spectra of E15 and E16 have identical predominant product ions with $m / z 137.0603\left(\left[\mathrm{C}_{8} \mathrm{H}_{9} \mathrm{O}_{2}\right]^{+}\right)$and $m / z 107.0497\left(\left[\mathrm{C}_{7} \mathrm{H}_{7} \mathrm{O}\right]^{+}\right)$, which correlate with mono-hydroxylation on the NBOMe ring and $\mathrm{O}$-demethylation on the $2 \mathrm{C}$ ring. The main product ions used for the identification of the structure of metabolite E17 are $m / z 193.1229\left(\left[\mathrm{C}_{12} \mathrm{H}_{17} \mathrm{O}_{2}\right]^{+}\right)$and $123.0446\left(\left[\mathrm{C}_{7} \mathrm{H}_{7} \mathrm{O}_{2}\right]^{+}\right)$, which are formed by amine cleavage and dealkylation respectively. The five different mono-hydroxylated metabolites (E21-E25: $\mathrm{C}_{20} \mathrm{H}_{27} \mathrm{NO}_{4}$ precursor ion $[\mathrm{M}+\mathrm{H}]^{+} \mathrm{m} / \mathrm{z} 346.2013$ ) were identified as follows: For metabolites E21 and E22 the same structure was identified. The mass spectra of $\mathrm{E} 21$ and E22 display the product ions $\mathrm{m} / \mathrm{z} 209.1178\left(\left[\mathrm{C}_{12} \mathrm{H}_{17} \mathrm{O}_{3}\right]^{+}\right), \mathrm{m} / \mathrm{z} 179.1072$ $\left(\left[\mathrm{C}_{11} \mathrm{H}_{15} \mathrm{O}_{2}\right]^{+}\right)$, and the two specific NBOMe part ions $\mathrm{m} / \mathrm{z} 121.0653$ and $\mathrm{m} / \mathrm{z}$ 91.0534. The hydroxylation takes place at $\alpha$-position due to the following observations: the product ion with $\mathrm{m} / \mathrm{z}$

This article is protected by copyright. All rights reserved. 
209.1178 correlates with the hydroxylation on the 2C part and is formed by amine cleavage; the product ion of $m / z 179.1072$ can only occur when the hydroxylation does not take place on the 4ethyl-1-methyl-2,5-dimethoxyphenyl and is formed by $\alpha$-cleavage. The mass spectrum obtained for $\mathrm{E} 23$ leads us to the conclusion that the hydroxylation must occur on the $2 \mathrm{C}$ part. $\mathrm{E} 24$ fragmentation resulted in product ions of $m / z 193.1229\left(\left[\mathrm{C}_{12} \mathrm{H}_{17} \mathrm{O}_{2}\right]^{+}\right), \mathrm{m} / z 137.0603\left(\left[\mathrm{C}_{8} \mathrm{H}_{9} \mathrm{O}_{2}\right]^{+}\right)$and $\mathrm{m} / \mathrm{z} 107.0497$

$\left(\left[\mathrm{C}_{7} \mathrm{H}_{7} \mathrm{O}\right]^{+}\right)$, correlating with dealkylation and $\alpha^{\prime}$-cleavage. The combination of these product ions unambiguously identifies the vicinal position as site of hydroxylation.

\subsubsection{N-NBOMe}

$25 \mathrm{~N}-\mathrm{NBOMe}$ transformation resulted in the fewest number or metabolites: 24 in total in pHLM and 9 in fungi $C$. elegans. The mass spectrum of $25 \mathrm{~N}-\mathrm{NBOMe}$ (precursor ion $[\mathrm{M}+\mathrm{H}]^{+} \mathrm{m} / \mathrm{z} 347.1601$ ) shows the molecular ion and the product ions with $\mathrm{m} / \mathrm{z} 121.0653$ and $\mathrm{m} / \mathrm{z} 91.0534$. When a product ion with $\mathrm{m} / \mathrm{z} 210.0766\left(\left[\mathrm{C}_{10} \mathrm{H}_{12} \mathrm{NO}_{4}\right]^{+}\right)$was present, no biotransformation took place on the $2 \mathrm{C}$ part. Oxidative $O$-demethylation on the $2 \mathrm{C}$ part resulted in a product ion with $\mathrm{m} / z 196.0610\left(\left[\mathrm{C}_{9} \mathrm{H}_{10} \mathrm{NO}_{4}\right]^{+}\right)$. The metabolite resulting from the reduction of the aromatic nitro group (N8 precursor ion $[\mathrm{M}+\mathrm{H}]^{+}$ $m / z$ 317.1860) fragmented into $m / z 180.1014\left(\left[\mathrm{C}_{10} \mathrm{H}_{14} \mathrm{NO}_{2}\right]^{+}\right), \mathrm{m} / z$ $165.0781\left(\left[\mathrm{C}_{9} \mathrm{H}_{11} \mathrm{NO}_{2}\right]^{+}\right), \mathrm{m} / \mathrm{z}$ 121.0653 and $\mathrm{m} / \mathrm{z} 91.0534$ due to cleavage of the amine, $\alpha$-cleavage and the two product ions representing the intact NBOMe part. The site of $O$-demethylation occurring for metabolites $\mathrm{N} 6$ and N7 $\left(\mathrm{C}_{17} \mathrm{H}_{22} \mathrm{~N}_{2} \mathrm{O}_{3}\right.$ precursor ion $[\mathrm{M}+\mathrm{H}]^{+} \mathrm{m} / \mathrm{z}$ 303.1703) was differentiated by the presence of the product ions $m / z 166.0868\left(\left[\mathrm{C}_{9} \mathrm{H}_{12} \mathrm{NO}_{2}\right]^{+}\right), \mathrm{m} / z 121.0653$ and $\mathrm{m} / \mathrm{z} 91.0534$, with the first one being formed by amine cleavage and the two characteristic ions for NBOMe part fragments and denote $O$ demethylation on the $2 \mathrm{C}$ part (N7). Opposed to this, the occurrence of the product ion $\mathrm{m} / \mathrm{z} 180.1025$ $\left(\left[\mathrm{C}_{10} \mathrm{H}_{14} \mathrm{NO}_{2}\right]^{+}\right.$) (also occurring for $\mathrm{N} 8$ ), which correlates with an intact 4-ethyl-2,5-dimethoxyaniline, implying O-demethylation taking place on the NBOMe part (N6). For metabolites N9-N11 $\left(\mathrm{C}_{16} \mathrm{H}_{18} \mathrm{~N}_{2} \mathrm{O}_{5}\right.$ precursor ion $[\mathrm{M}+\mathrm{H}]^{+} \mathrm{m} / \mathrm{z}$ 319.1288) the sites of di-O-demethylation were also differentiated by the presence (N9) or absence (N10, N11) of the NBOMe part product ions. Additionally, the mass spectra of $\mathrm{N} 10$ and $\mathrm{N} 11$ displayed the product ions $\mathrm{m} / \mathrm{z} 196.0610$ $\left(\left[\mathrm{C}_{9} \mathrm{H}_{10} \mathrm{NO}_{4}\right]^{+}\right)$and $m / z 107.497\left(\left[\mathrm{C}_{7} \mathrm{H}_{7} \mathrm{O}\right]^{+}\right)$, correlating with amine cleavage and dealkylation, and can both only occur if $O$-demethylation occurs simultaneously on the $2 \mathrm{C}$ and NBOMe part. Nevertheless, the site of $O$-demethylation on the $2 \mathrm{C}$ part could not be determined. Accordingly, metabolites N12, $\mathrm{N} 13$ and $\mathrm{N} 14\left(\mathrm{C}_{17} \mathrm{H}_{20} \mathrm{~N}_{2} \mathrm{O}_{5}\right.$ precursor ion $[\mathrm{M}+\mathrm{H}]^{+} \mathrm{m} / z$ 333.1445) were identified, with the mass spectra of $\mathrm{N} 12$ and $\mathrm{N} 13$ displaying the two NBOMe part product ions, and hence, $\mathrm{O}$-demethylation occurring on the $2 \mathrm{C}$ part and the product ions $m / z 210.0766\left(\left[\mathrm{C}_{10} \mathrm{H}_{12} \mathrm{NO}_{4}\right]^{+}\right)$and $m / z 107.497\left(\left[\mathrm{C}_{7} \mathrm{H}_{7} \mathrm{O}\right]^{+}\right)$, which can only occur if the $2 \mathrm{C}$ part is intact and $\mathrm{O}$-demethylation taking place on the NBOMe part, respectively. The $O$-demethylated and hydroxylated metabolites (N15- $\mathrm{N} 18: \mathrm{C}_{17} \mathrm{H}_{20} \mathrm{~N}_{2} \mathrm{O}_{6}$ precursor ion $[\mathrm{M}+\mathrm{H}]^{+} \mathrm{m} / \mathrm{z}$ 349.1394) were identified by using mainly the NBOMe part fragments and the product ions $m / z 137.0603\left(\left[\mathrm{C}_{8} \mathrm{H}_{9} \mathrm{O}_{2}\right]^{+}\right), m / z 123.0446\left(\left[\mathrm{C}_{7} \mathrm{H}_{7} \mathrm{O}_{2}\right]^{+}\right)$, the exact site of hydroxylation was determined as follows: The predominant product ions in the mass spectrum of $\mathrm{N} 15 \mathrm{~m} / \mathrm{z} 210.0766$ $\left(\left[\mathrm{C}_{10} \mathrm{H}_{12} \mathrm{NO}_{4}\right]^{+}\right)$and $m / z 123.0446\left(\left[\mathrm{C}_{7} \mathrm{H}_{7} \mathrm{O}_{2}\right]^{+}\right)$, are formed by amine cleavage and dealkylation. It can be concluded that the $2 \mathrm{C}$ part is intact and that both $O$-demethylation and hydroxylation must occur on the NBOMe part. The mass spectrum of N16 resulted in very little fragmentation with the precursor ion $\mathrm{m} / \mathrm{z} 349.1394$ and two product ions $\mathrm{m} / \mathrm{z} 121.0653$ and $\mathrm{m} / \mathrm{z}$ 91.0534. Therefore, it was only possible to conclude the site of $O$-demethylation to be on the $2 \mathrm{C}$ part. Due to the absence of further product ions it is more likely that the hydroxylation also occurs on the 2,5-dimethoxy-4-

This article is protected by copyright. All rights reserved. 
nitrophenyl. For $\mathrm{N} 17$ the fragmentation was similar, with the precursor ion and two product ions $m / z 137.0603\left(\left[\mathrm{C}_{8} \mathrm{H}_{9} \mathrm{O}_{2}\right]^{+}\right)$and $m / z 123.0446\left(\left[\mathrm{C}_{7} \mathrm{H}_{7} \mathrm{O}_{2}\right]^{+}\right)$. Hence, $\mathrm{O}$-demethylation must occur on the NBOMe part. The site of hydroxylation could only be narrowed down to the NBOMe part. Due to the absence of product ions formed by $\alpha$ and $\beta$ cleavage it is more likely that the hydroxylation occurs on the 2,5-dimethoxy-4-nitrophenyl. The mass spectrum of $\mathrm{N} 18$ was a bit more complicated to interpret. $\mathrm{N} 18$ fragmented into the following product ions $\mathrm{m} / \mathrm{z} 227.1026\left(\left[\mathrm{C}_{10} \mathrm{H}_{15} \mathrm{~N}_{2} \mathrm{O}_{4}\right]^{+}\right), \mathrm{m} / \mathrm{z}$ $210.0766\left(\left[\mathrm{C}_{10} \mathrm{H}_{12} \mathrm{~N}_{2} \mathrm{O}_{4}\right]^{+}\right), m / z 195.0532\left(\left[\mathrm{C}_{9} \mathrm{H}_{9} \mathrm{NO}_{4}\right]^{+}\right), m / z 137.0603\left(\left[\mathrm{C}_{8} \mathrm{H}_{9} \mathrm{O}_{2}\right]^{+}\right)$and $m / z 123.0446$. These are formed by dealkylation, amine cleavage, a further loss of a methyl radical and dealkylation, respectively ${ }^{42}$. Hencem both $\mathrm{O}$-demethylation and hydroxylation must occur on the $2 \mathrm{C}$ part. The fragmentation of $\mathrm{N} 19\left(\mathrm{C}_{20} \mathrm{H}_{26} \mathrm{~N}_{2} \mathrm{O}_{4}\right.$ precursor ion $\left.[\mathrm{M}+\mathrm{H}]^{+} \mathrm{m} / \mathrm{z} 359.1965\right)$ displayed the following product ions: $m / z 237.1239\left(\left[\mathrm{C}_{12} \mathrm{H}_{17} \mathrm{~N}_{2} \mathrm{O}_{3}\right]^{+}\right), \mathrm{m} / z 222.1130\left(\left[\mathrm{C}_{12} \mathrm{H}_{16} \mathrm{NO}_{3}\right]^{+}\right), \mathrm{m} / z 121.0653$ and $m / z$ 91.0534, which are formed by dealkylation and amine cleavage, respectively. The mass spectrum of $\mathrm{N} 20\left(\mathrm{C}_{18} \mathrm{H}_{20} \mathrm{~N}_{2} \mathrm{O}_{6}\right.$ precursor ion $[\mathrm{M}+\mathrm{H}]^{+} \mathrm{m} / z$ 359.1965) showed very little fragmentation with the two NBOMe part ions and product ion $\mathrm{m} / z 239.0668\left(\left[\mathrm{C}_{10} \mathrm{H}_{11} \mathrm{~N}_{2} \mathrm{O}_{5}\right]^{+}\right)$, the latter being formed by dealkylation. Therefore, the oxidation of secondary alcohols can only occur on $\alpha$ - or $\beta$ position. The identification of the structures of the mono-hydroxylated metabolites N21- N24 $\left(\mathrm{C}_{18} \mathrm{H}_{22} \mathrm{~N}_{2} \mathrm{O}_{6}\right.$ precursor ion $[\mathrm{M}+\mathrm{H}]^{+} \mathrm{m} / 2$ 363.1551) is more complicated due to little fragmentation. Metabolite N21 fragmented into the two NBOMe part product ions and therefore the hydroxylation must occur on the $2 \mathrm{C}$ part. It is eluting $1.66 \mathrm{~min}$ after the parent substrate and is consequently identified as an $\mathrm{N}$-oxide metabolite. $\mathrm{N}$-oxides typically elute after the parent substrate on a reverse phase column ${ }^{27,}{ }^{41}$. The fragmentation of $\mathrm{N} 22$ displayed the product ions $\mathrm{m} / \mathrm{z} 345.1450$ $\left(\left[\mathrm{C}_{18} \mathrm{H}_{21} \mathrm{~N}_{2} \mathrm{O}_{5}\right]^{+}\right), m / z 121.0653$ and $m / z$ 91.0534. The first one is formed by cleavage of the hydroxyl on the amine and the rearrangement forming a double bound. Therefore N22 was identified to be a hydroxylamine metabolite. The position of hydroxylation of $\mathrm{N} 23$ and $\mathrm{N} 24$ was identified to be 5 position on the NBOMe part ring using the product ions $m / z 137.0603\left(\left[\mathrm{C}_{8} \mathrm{H}_{9} \mathrm{O}_{2}\right]^{+}\right), m / z 109.0645$ $\left(\left[\mathrm{C}_{6} \mathrm{H}_{5} \mathrm{O}_{2}\right]^{+}\right)$, and $m / z 107.0485$ correlating with dealkylation, simultaneous cleavage of the NBOMe ring and the methyl on the methoxy group forming a protonated chinone.

\subsection{Microsomal biotransformation}

Incubation of pHLM with 25D-NBOMe, 25E-NBOMe and 25N-NBOMe resulted in 36, 26 and 24 metabolites, respectively. Several different biotransformational mechanisms were observed in all three 25X-NBOMe compounds. Hydroxylation of the parent substrate $(+15.995 \mathrm{Da})$ formed six 25DNBOMe metabolites (D21-D26), five 25E-NBOMe metabolites (E21-E25) and three 25N-NBOMe metabolites (N22-N24). Hydroxylation of the parent compound was observed at $\alpha$-position for D22, E21 and E22, $\beta$ - or $\alpha$-position for D23, D25 and $\alpha$-position or on the amine for D26, E23, E25 and N22. D23, D25 and N22 were further metabolised by oxidation of the secondary alcohol forming D20 and N20. For both D24 and E24 hydroxylation was identified to be on the vicinal position. Two Noxide metabolites were observed (D27/ N21) both eluting after the parent substrates, which is typical for $\mathrm{N}$-oxides on reversed phase columns ${ }^{27,41}$. The resulting mono-hydroxylated metabolites underwent further oxidative O-demethylation (D10-D19/ E12-E19/ N15-N18; mass difference to parent substrate -14.0157 Da) on the 2C part (D10-D12, D14, D15, D17, D19/ E12-E16, E19/ N16) or on the NBOMe part (D16/ E17 / N15, N17, N18). Oxidative O-demethylation of the parent compound (mass difference to parent $-14.0156 \mathrm{Da}$ ) on either the $2^{\text {nd }}$ or $5^{\text {th }}$ position of the $2 \mathrm{C}$ part or $2^{\text {nd }}$ position on the NBOMe part was observed for all three compounds resulting in three metabolites (D7/ E8/

This article is protected by copyright. All rights reserved. 
N12; D8/ E7/ N13; D9/ E9/ N14;). Further oxidative O-demethylation (mass difference to parent substrate $-28.0312 \mathrm{Da}$ ) of these metabolites resulted in metabolites found for all three tested $25 \mathrm{X}$ NBOMes (D4/ E6/ N9; D5/ E5/ N10; D6/ N11;). Only for E6 further metabolisation occurred, forming a di-O-demethylated and hydroxylated metabolite E10 and E11. For all three substrates, the respective 2,5-dimethoxyphenethylamine (2C-X) metabolites could be identified (D2, E3, N3) formed by oxidative $\mathrm{N}$-dealkylation (-120.0575 Da). 2C-X are also biologically active compounds used for recreational purposes and have been previously identified as 25B-NOMe and 25I-NBOMe metabolites ${ }^{4}$. This $2 \mathrm{C}-\mathrm{X}$ metabolite was further metabolised by oxidative deamination forming 2 methoxybenzoic acid (D1/ E1/ N1; precursor ion $[\mathrm{M}+\mathrm{H}]^{+} \mathrm{m} / \mathrm{z}$ 153.0546), identical for all three substrates. For 25E-NBOMe and 25N-NBOMe E3 and N3 were further metabolised by oxidative $O$ demethylation to $\mathrm{E} 2$ and $\mathrm{N} 2$ (precursor ion $[\mathrm{M}+\mathrm{H}]^{+} \mathrm{m} / \mathrm{z} 196.1332$ and $\mathrm{m} / \mathrm{z}$ 213.0870). The 25DNBOMe and 25E-NBOMe 2C-X metabolites were hydroxylated forming D3 and E4. For metabolites D27 (precursor ion $[\mathrm{M}+\mathrm{H}]^{+} \mathrm{m} / \mathrm{z}$ 346.1649) and E26 (precursor ion $[\mathrm{M}+\mathrm{H}]^{+} \mathrm{m} / \mathrm{z}$ 360.1806) carboxylation of the primary alcohol or alkyl was observed, respectively.

Biotransformation of 25E-NBOMe and 25D-NBOMe was very similar. However, 25D-NBOMe produced seven additional dihydroxylated metabolites (D30-36, precursor ion $[\mathrm{M}+\mathrm{H}]^{+} \mathrm{m} / \mathrm{z}$ 348.1806), which could neither be found for 25E-NBOMe nor for 25N-NBOMe. Sites of dihydroxylation were for D30 in $\alpha$ and vicinal position, for which in vicinal position oxidation of a primary alcohol took place. Metabolites D31 and D32 had the hydroxylations taking place on the $2 \mathrm{C}$ ring and in $\alpha$-position (D32) or $\beta$-position (D31). Whereas for D33 it could be undoubtedly determined that a hydroxylamine was formed and a second hydroxylation took place in $\alpha$-position. Metabolites D35 and D36 had hydroxylation occurring on the NBOMe ring and in vicinal position. Unique $25 \mathrm{~N}-\mathrm{NBOMe}$ metabolites were formed due to reduction of the aromatic nitro group at the 4position (N8, precursor ion $[\mathrm{M}+\mathrm{H}]^{+} \mathrm{m} / \mathrm{z} 317.1860$ ), which was further metabolised by oxidative $O$ demethylation (N6, N7, precursor ion $[\mathrm{M}+\mathrm{H}]^{+} \mathrm{m} / \mathrm{z}$ 303.1703), or $\mathrm{N}$-acetylation of the primary aromatic amine (N19, precursor ion $\left.[\mathrm{M}+\mathrm{H}]^{+} \mathrm{m} / \mathrm{z} 359.1965\right)$.

In summary, the observed biotransformation pathways of 25D-NBOMe were oxidative $O$ deamination, oxidative $\mathrm{N}$-dealkylation also in combination with hydroxylation, oxidative $\mathrm{O}$ demethylation possibly combined with hydroxylation, oxidation of secondary alcohols, mono- and dihydroxylation, oxidation of primary alcohols and carboxylation of primary alcohols. For $25 \mathrm{E}-$ NBOMe the same metabolism steps were observed differing in the sites of metabolic modifications. Additionally, oxidative di-O-demethylation was seen. $25 \mathrm{~N}-\mathrm{NBOME}$ metabolism was very similar to 25D-NBOMe and 25E-NBOMe, with mostly the same steps observed. In addition, due to the presence of the aromatic nitro group, the following mechanisms were observed: reduction of the aromatic nitro group, also in combination with demethylation and $\mathrm{N}$-acetylation of the primary aromatic amine.

Meteor Nexus was a helpful aid in the evaluation of obtained IDA-LC-HR-MS/MS data in combination with the MasterView ${ }^{\mathrm{TM}}$ software. Nevertheless, a critical interpretation of data is necessary using described parameters. Every hit passing this criterion must then be manually checked if the peak was a peak or simply noise and if the isotopic ratio was correct. The mass spectra are then used to unambiguously identify a metabolite. Only 19 metabolites were not predicted by Meteor Nexus but identified by the authors using the gained knowledge about typical fragmentation patterns. 
Therefore, the in silico predictions provided by Meteor Nexus are a valuable tool for data evaluation but nevertheless need to be assessed critically.

Caspar et al. ${ }^{4}$ reported 35 phase I metabolites of 25B-NBOMe of which 13 followed the same biotransformation pathways as 35 metabolites of the 90 metabolites found for 25D-NBOMe, 25ENBOMe and 25N-NBOMe. N-oxides and hydroxylamines of 25X-NBOMes were identified in the present study, which have not yet been reported in literature.

\subsection{Microbial biotransformation}

Microbial experiments incubations of 25D-NBOMe, 25E-NBOMe or 25N-NBOMe with C. elegans generated 14, 11 and 9 metabolites, respectively. Each metabolite found in fungi was also identified in pHLM. Metabolites were identified according to their precursor ion, fragmentation, isotope ratios and retentions times, which were the same as for the metabolites found in previous experiments with pHLM. Biotransformation steps observed in fungi $C$. elegans were oxidative $\mathrm{N}$-dealkylation, oxidative $\mathrm{O}$-demethylation also in combination with hydroxylation, oxidation of secondary alcohols and mono- and di-hydroxylation for all three compounds, and for 25N-NBOMe additionally reduction of the aromatic nitro groups and $\mathrm{N}$-hydroxylation of secondary aliphatic amines. For 25DNBOMe and 25N-NBOMe also $\mathrm{N}$-oxide formation and hydroxylamine metabolites were identified.

The microsomal method of pHLM generated three times more metabolites than the microbial method of the fungi $C$. elegans. Watanabe et al. ${ }^{32}$ reported to have found more metabolites of JWH018 and other similar synthetic cannabinoids, in C. elegans than literature data reports found in pHLM. But Watanabe et al. used a different $C$. elegans line, which could explain different results. The ability of the fungi $C$. elegans to metabolise xenobiotics and especially NPS could depend on the chemical class of the drug. Therefore, it is advised to conduct more metabolism studies with $C$. elegans, investigating different chemical classes of NPS, in order to be able to conclude the fungi's ability to be a good metabolism model.

\section{Conclusion}

Microsomal and microbial experiments resulted in thirty-six 25D-NBOMe phase I metabolites, twenty-six 25E-NBOMe phase I metabolites and twenty-four 25N-NBOMe phase I metabolites. One metabolite identical for all three compounds was found (E1/ D1/ N1). For the first time, an $\mathrm{N}$-oxide 25X-NBOMe metabolite was identified, namely D27 and N21, which eluted 0.91 min and 1.66 min after the parent substrate, respectively. Additionally, hydroxylamine metabolites were identified due to their fragmentation (D11, D12, D17, D26, D33; E12, E13, E14, E19, E23, E25; N22). For 25NNBOMe unique metabolites were detected due to the reduction of the aromatic nitro group. Main biotransformation steps observed were oxidative $\mathrm{O}$-demethylation, mono and dihydroxylation, $\mathrm{N}$ oxide formation, hydroxylamine formation and $\mathrm{N}$-dealkylation. Additionally, metabolites found in both pHLM and fungi $C$. elegans were eluting at the same retention times and could therefore be identified according their retention times. The fungi $C$. elegans could generate all main phase $I$ biotransformation steps observed for all three compounds and therefore is an interesting model for further studies of NPS metabolism. Nevertheless, in the current study no phase II metabolites were identified in the fungi $C$. elegans samples. When authentic biological samples of consumers of 25DNBOMe, $25 \mathrm{E}-\mathrm{NBOMe}$ or $25 \mathrm{~N}-\mathrm{NBOMe}$ are available, these metabolites can be used for target analysis, and might confirm the predictions from in-vitro experiments to some extent. Additionally, 
phase II metabolites (e.g. glucuronides) might be present in urine samples, which might have similar mass spectrometric product ions.

\section{Acknowledgments}

The authors would like to thank Yannik Winter and Patricia Wybraniec for assisting with the fungi experiments, and Dr. Susanne Nussbaumer, Achim Caspar and Dr. Patrick Juchli for fruitful discussions. Additionally, the authors would like to thank Dr. Daniel Pasin for thorough proof reading of the manuscript for language mistakes and Prof. W.M.A. Niessen for his help with the interpretation of metabolite N18.

\section{Funding}

This research received financial support by the Swiss Federal Office of Public Health (BAG project Nr. 15.029013).

\section{Conflict of Interest}

The authors declare no conflict of interest.

\section{References}

1 Chatwin C. Assessing the 'added value' of European policy on new psychoactive substances. Int J Drug Policy 2017; 40:111-116. DOI: 10.1016/j.drugpo.2016.11.002.

2 EMCDDA. European Drug Report 2017: Trends and Developments. Publications Office of the European Union, Luxembourg., doi:10.2810/610791, 2017 (EDND) TEisadond. The European information system and database on new drugs (EDND). [webpage] 2018; 07.02.2018 [cited 2018 15.02.2018].

4 Caspar AT, Brandt SD, Stoever AE, Meyer MR, Maurer HH. Metabolic fate and detectability of the new psychoactive substances 2-(4-bromo-2,5-dimethoxyphenyl)- $\mathrm{N}-[(2-$ methoxyphenyl)methyl]ethanamine (25B-NBOMe) and 2-(4-chloro-2,5-dimethoxyphenyl)-N[(2-methoxyphenyl)methyl] ethanamine (25C-NBOMe) in human and rat urine by GC-MS, LCMSn, and LC-HR-MS/MS approaches. J Pharm Biomed Anal 2017; 134:158-169. DOI: 10.1016/j.jpba.2016.11.040.

5 Suzuki J, Dekker MA, Valenti ES, et al. Toxicities associated with NBOMe ingestion-a novel class of potent hallucinogens: a review of the literature. Psychosomatics 2015; 56(2):129-39. DOI: 10.1016/j.psym.2014.11.002.

6 Boumrah Y, Humbert L, Phanithavong M, Khimeche K, Dahmani A, Allorge D. In vitro characterization of potential CYP- and UGT-derived metabolites of the psychoactive drug 25B-NBOMe using LC-high resolution MS. Drug Test Anal 2016; 8(2):248-56. DOI: 10.1002/dta.1865.

7 Poklis JL, Raso SA, Alford KN, Poklis A, Peace MR. Analysis of 25I-NBOMe, 25B-NBOMe, 25CNBOMe and other dimethoxyphenyl-N-[(2-Methoxyphenyl) methyl]ethanamine derivatives on blotter paper. J Anal Toxicol 2015; 39(8):617-23. DOI: 10.1093/jat/bkv073.

8 Heim R. Synthese und Pharmakologie potenter 5-HT2A-Rezeptoragonisten mit N-2Methoxybenzyl-Partialstruktur Entwicklung eines neuen Struktur-Wirkungskonzepts. , in Fachbereich Biologie, Chemie, Pharmazie2003; Freie Universität Berlin: Berlin, Germany.333.

9 Hansen M. Design and synthesis of selective serotonin receptor agonists for positron emission tomography imaging of the brain, in Faculty of Pharmaceutical Sciences2010; University of Copenhagen: Copenhagen, Denmark.227. 
10 Glennon RA, Dukat M, el-Bermawy $M$, et al. Influence of amine substituents on 5-HT2A versus 5-HT2C binding of phenylalkyl- and indolylalkylamines. J Med Chem 1994; 37(13):1929-35.

11 Nichols DE, Sassano MF, Halberstadt AL, et al. N-Benzyl-5-methoxytryptamines as Potent Serotonin 5-HT2 Receptor Family Agonists and Comparison with a Series of Phenethylamine Analogues. ACS Chem Neurosci 2015; 6(7):1165-75. DOI: 10.1021/cn500292d.

12 Braden MR, Parrish JC, Naylor JC, Nichols DE. Molecular interaction of serotonin 5-HT2A receptor residues Phe339(6.51) and Phe340(6.52) with superpotent N-benzyl phenethylamine agonists. Mol Pharmacol 2006; 70(6):1956-64. DOI: 10.1124/mol.106.028720.

13 Lowe LM, Peterson BL, Couper FJ. A case review of the first analytically confirmed 25INBOMe-related death in Washington State. J Anal Toxicol 2015; 39(8):668-71. DOI: 10.1093/jat/bkv092.

14 Rickli A, Luethi D, Reinisch J, Buchy D, Hoener MC, Liechti ME. Receptor interaction profiles of novel N-2-methoxybenzyl (NBOMe) derivatives of 2,5-dimethoxy-substituted phenethylamines (2C drugs). Neuropharmacology 2015; 99:546-53. DOI: 10.1016/j.neuropharm.2015.08.034.

15 Hill SL, Doris T, Gurung S, et al. Severe clinical toxicity associated with analytically confirmed recreational use of 25I-NBOMe: case series. Clin Toxicol (Phila) 2013; 51(6):487-92. DOI: 10.3109/15563650.2013.802795.

16 Hermanns-Clausen M, Angerer V, Kithinji J, Grumann C, Auwarter V. Bad trip due to 25INBOMe: a case report from the EU project SPICE II plus. Clin Toxicol (Phila) 2017. 10.1080/15563650.2017.1319572:1-3. DOI: 10.1080/15563650.2017.1319572.

17 Bersani FS, Corazza O, Albano G, et al. 25C-NBOMe: preliminary data on pharmacology, psychoactive effects, and toxicity of a new potent and dangerous hallucinogenic drug. Biomed Res Int 2014; 2014:734749. DOI: 10.1155/2014/734749.

18 Liechti M. Novel psychoactive substances (designer drugs): overview and pharmacology of modulators of monoamine signaling. Swiss Med Wkly 2015; 145:w14043. DOI: 10.4414/smw.2015.14043.

19 Tang MH, Ching CK, Tsui MS, Chu FK, Mak TW. Two cases of severe intoxication associated with analytically confirmed use of the novel psychoactive substances 25B-NBOMe and 25CNBOMe. Clin Toxicol (Phila) 2014; 52(5):561-5. DOI: 10.3109/15563650.2014.909932.

20 Duffau B, Camargo C, Kogan M, Fuentes E, Cassels BK. Analysis of 25 C NBOMe in seized blotters by HPTLC and GC-MS. J Chromatogr Sci 2016; 54(7):1153-8. DOI: 10.1093/chromsci/bmw095.

21 Zuba D, Sekula K, Buczek A. 25C-NBOMe--new potent hallucinogenic substance identified on the drug market. Forensic Sci Int 2013; 227(1-3):7-14. DOI: 10.1016/j.forsciint.2012.08.027.

22 Rajotte JW, Palmentier JFP, Wallage HR. Drug recognition evaluation and chemical confirmation of a 25C-NBOMe-impaired driver. J Forensic Sci 2017; 62(5):1410-1413. DOI: 10.1111/1556-4029.13433.

23 Laskowski LK, Elbakoush F, Calvo J, et al. Evolution of the NBOMes: 25C- and 25B- sold as 25I-NBOMe. J Med Toxicol 2015; 11(2):237-41. DOI: 10.1007/s13181-014-0445-9.

24 Gee P, Schep L, Jensen BP, Moore G, Barrington S. Case series: toxicity from 25B-NBOMe--a cluster of N-bomb cases. Clin Toxicol (Phila) 2016; 54(2):141-6. DOI: 10.3109/15563650.2015.1115056.

25 Franz F, Angerer V, Moosmann B, Auwarter V. Phase I metabolism of the highly potent synthetic cannabinoid MDMB-CHMICA and detection in human urine samples. Drug Test Anal 2017; 9(5):744-753. DOI: 10.1002/dta.2049.

26 Franz F, Angerer V, Brandt SD, et al. In vitro metabolism of the synthetic cannabinoid 3,5-ABCHMFUPPYCA and its 5,3-regioisomer and investigation of their thermal stability. Drug Test Anal 2017; 9(2):311-316. DOI: 10.1002/dta.1950. 
27 Grafinger KE, Hadener M, Konig S, Weinmann W. Study of the in vitro and in vivo metabolism of the tryptamine 5-MeO-MiPT using human liver microsomes and real case samples. Drug Test Anal 2017. 10.1002/dta.2245. DOI: 10.1002/dta.2245. Richter LHJ, Flockerzi V, Maurer HH, Meyer MR. Pooled human liver preparations, HepaRG, or HepG2 cell lines for metabolism studies of new psychoactive substances? A study using MDMA, MDBD, butylone, MDPPP, MDPV, MDPB, 5-MAPB, and 5-API as examples. J Pharm Biomed Anal 2017; 143:32-42. DOI: 10.1016/j.jpba.2017.05.028.

29 Zhang D, Yang Y, Leakey JE, Cerniglia CE. Phase I and phase II enzymes produced by Cunninghamella elegans for the metabolism of xenobiotics. FEMS Microbiol Lett 1996; 138(2-3):221-6.

30 Wang RF, Cao WW, Khan AA, Cerniglia CE. Cloning, sequencing, and expression in Escherichia coli of a cytochrome P450 gene from Cunninghamella elegans. FEMS Microbiol Lett 2000; 188(1):55-61.

31 Asha S, Vidyavathi M. Cunninghamella--a microbial model for drug metabolism studies--a review. Biotechnol Adv 2009; 27(1):16-29. DOI: 10.1016/j.biotechadv.2008.07.005.

32 Watanabe S, Kuzhiumparambil U, Winiarski Z, Fu S. Biotransformation of synthetic cannabinoids JWH-018, JWH-073 and AM2201 by Cunninghamella elegans. Forensic Sci Int 2016; 261:33-42. DOI: 10.1016/j.forsciint.2015.12.023.

33 Watanabe S, Kuzhiumparambil U, Nguyen MA, Cameron J, Fu S. Metabolic profile of synthetic cannabinoids 5F-PB-22, PB-22, XLR-11 and UR-144 by Cunninghamella elegans. AAPS J 2017; 19(4):1148-1162. DOI: 10.1208/s12248-017-0078-4.

34 Dube AK, Kumar MS. Biotransformation of bromhexine by Cunninghamella elegans, C. echinulata and C. blakesleeana. Braz J Microbiol 2017; 48(2):259-267. DOI: 10.1016/j.bjm.2016.11.003.

35 Nielsen LM, Holm NB, Leth-Petersen S, Kristensen JL, Olsen L, Linnet K. Characterization of the hepatic cytochrome P450 enzymes involved in the metabolism of 25I-NBOMe and 25INBOH. Drug Test Anal 2017; 9(5):671-679. DOI: 10.1002/dta.2031.

36 Marchant CA, Briggs KA, Long A. In silico tools for sharing data and knowledge on toxicity and metabolism: derek for windows, meteor, and vitic. Toxicol Mech Methods 2008; 18(23):177-87. DOI: 10.1080/15376510701857320.

37 Leibniz-Institute-DMSZ. 186. UNIVERSAL MEDIUM FOR YEASTS (YM). 2007; [cited 2018 06.03.2018]; Available from: https://www.dsmz.de/microorganisms/medium/pdf/DSMZ Medium186.pdf.

38 Pasin D, Cawley A, Bidny S, Fu S. Characterization of hallucinogenic phenethylamines using high-resolution mass spectrometry for non-targeted screening purposes. Drug Test Anal 2017; 9(10):1620-1629. DOI: 10.1002/dta.2171.

39 Leth-Petersen S, Gabel-Jensen C, Gillings N, et al. Metabolic Fate of Hallucinogenic NBOMes. Chem Res Toxicol 2016; 29(1):96-100. DOI: 10.1021/acs.chemrestox.5b00450.

40 Bonse G, Metzler M. Biotransformationen organischer Fremdsubstanzen, Stuttgart, Germany: Georg Thime Verlag. 1181978.

41 Michely JA, Helfer AG, Brandt SD, Meyer MR, Maurer HH. Metabolism of the new psychoactive substances $\mathrm{N}, \mathrm{N}$-diallyltryptamine (DALT) and 5-methoxy-DALT and their detectability in urine by GC-MS, LC-MSn, and LC-HR-MS-MS. Anal Bioanal Chem 2015; 407(25):7831-42. DOI: 10.1007/s00216-015-8955-0.

42 Niessen WM, Correa RA. Interpreation of MS-MS mass spectra of drugs and pesticides Wiley Series on Mass Spectrometry, ed. D.M. Desiderioand J.A. Loo. 10.1002/9781119294269, Hoboken, USA: John Wiley \& Sons, Inc2017. 
Table 1 Identified metabolites of 25D-NBOMe in pHLM and Fungi C. elegans sorted by their protonated mass $[\mathrm{M}+\mathrm{H}]^{+}$. The three most abundant product ions of 25D-NBOMe and its metabolites are listed with their relative intensities (percentage of the base peak intensity) as indices numbers.

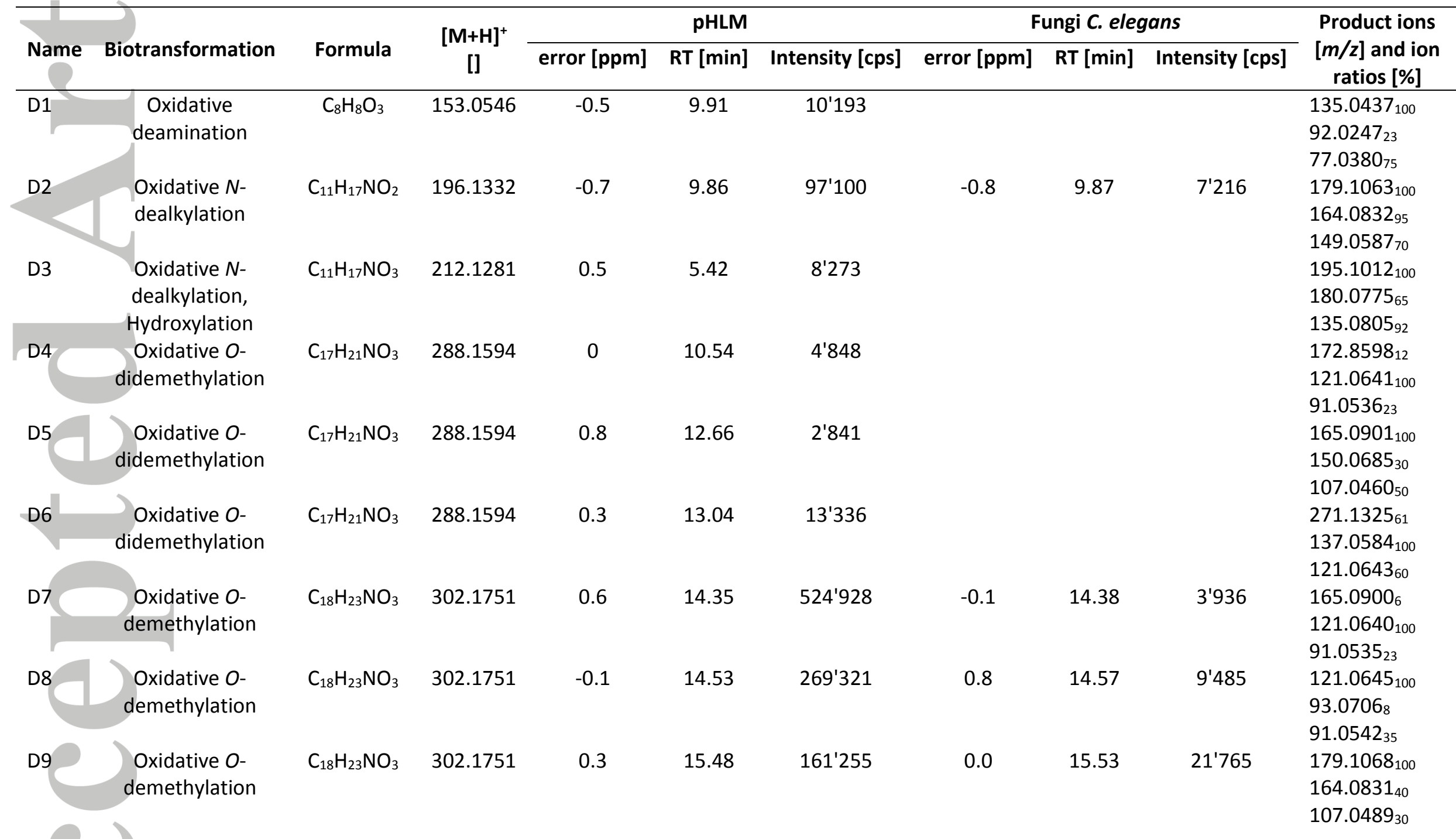

This article is protected by copyright. All rights reserved. 


\section{D-NBOMe}

c)

D10

Oxidative $O$ -

emethylation,

Hydroxylation

D11 Oxidative $O$ -

demethylation,

Hydroxylation

Oxidative $O$ -

demethylation, Hydroxylation

D13 Oxidative $O$ demethylation, Hydroxylation

D14 Oxidative $O$ Hydroxylation

D15 Oxidative $O$ -

demethylation, Hydroxylation

D16 Oxidative $O$ -

demethylation, Hydroxylation

D17 Oxidative $O$ demethylation, Hydroxylation

D18 Oxidative $O$ demethylation, Hydroxylation

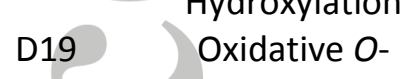

demethylation, Hydroxylation

\begin{tabular}{|c|c|c|c|c|}
\hline $\mathrm{C}_{19} \mathrm{H}_{25} \mathrm{NO}_{3}$ & 316.1907 & 0 & 17.38 & 7'095'732 \\
\hline $\mathrm{C}_{18} \mathrm{H}_{23} \mathrm{NO}_{4}$ & 318.1700 & 0.3 & 10.06 & 4'892 \\
\hline $\mathrm{C}_{18} \mathrm{H}_{23} \mathrm{NO}_{4}$ & 318.1700 & -0.3 & 10.26 & 5'155 \\
\hline $\mathrm{C}_{18} \mathrm{H}_{23} \mathrm{NO}_{4}$ & 318.1700 & 0.2 & 10.79 & 15'336 \\
\hline $\mathrm{C}_{18} \mathrm{H}_{23} \mathrm{NO}_{4}$ & 318.1700 & -1 & 10.81 & $12 ' 705$ \\
\hline $\mathrm{C}_{18} \mathrm{H}_{23} \mathrm{NO}_{4}$ & 318.1700 & -0.5 & 12.28 & 4'640 \\
\hline $\mathrm{C}_{18} \mathrm{H}_{23} \mathrm{NO}_{4}$ & 318.1700 & 0.9 & 12.60 & 3'415 \\
\hline $\mathrm{C}_{18} \mathrm{H}_{23} \mathrm{NO}_{4}$ & 318.1700 & 0.3 & 13.01 & $26^{\prime} 168$ \\
\hline $\mathrm{C}_{18} \mathrm{H}_{23} \mathrm{NO}_{4}$ & 318.1700 & -0.9 & 13.38 & $17^{\prime} 803$ \\
\hline $\mathrm{C}_{18} \mathrm{H}_{23} \mathrm{NO}_{4}$ & 318.1700 & -1.5 & 13.53 & 1'190 \\
\hline $\mathrm{C}_{18} \mathrm{H}_{23} \mathrm{NO}_{4}$ & 318.1700 & -0.2 & 15.07 & $1^{\prime} 461$ \\
\hline
\end{tabular}

0.7

17.36

12'608'060

179.1081 19

$1_{121.0644} 100$

$\mathbf{9 1 . 0 5 3 2}_{38}$

$121.0644_{100}$

$93.0702_{12}$

$91.0533_{30}$

$300.1581_{24}$

$121.0639_{100}$

$91.0535_{30}$

$151.0745_{15}$

$121.0640_{100}$

$91.0535_{24}$

No MS2

triggered

$165.0880_{15}$

$137.0587_{100}$

$107.481_{28}$

$181.0819_{37}$

$137.0597_{100}$

$121.0645_{82}$

$179.1065_{100}$

$164.0826_{39}$

$123.0433_{42}$

$300.1578_{33}$

$121.0642_{100}$

$91.0534_{35}$

No MS2

triggered

$121.0636_{100}$

$91.0547_{30}$

$93.0705_{20}$

This article is protected by copyright. All rights reserved. 


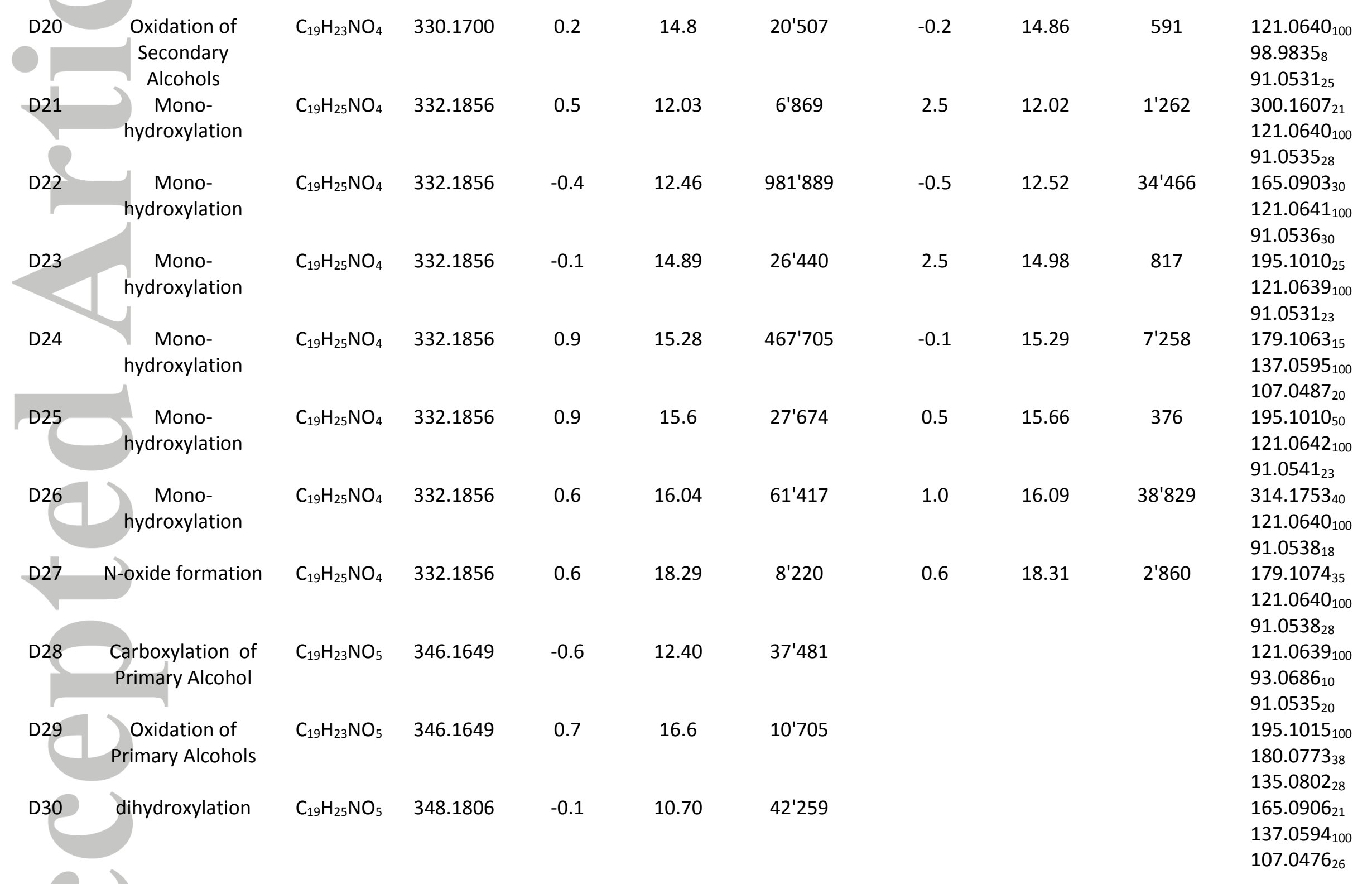

This article is protected by copyright. All rights reserved. 


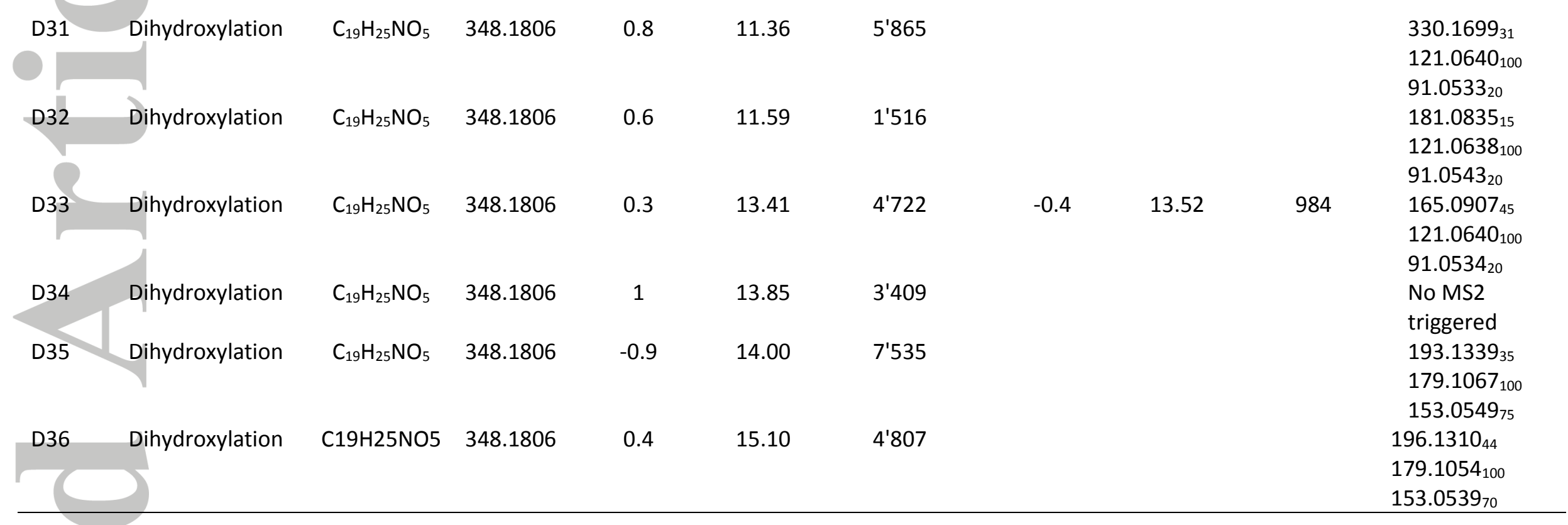

This article is protected by copyright. All rights reserved. 
Table 2 Identified metabolites of 25E-NBOMe identified in pHLM and fungi C. elegans sorted by their protonated mass [M+H] ${ }^{+}$.

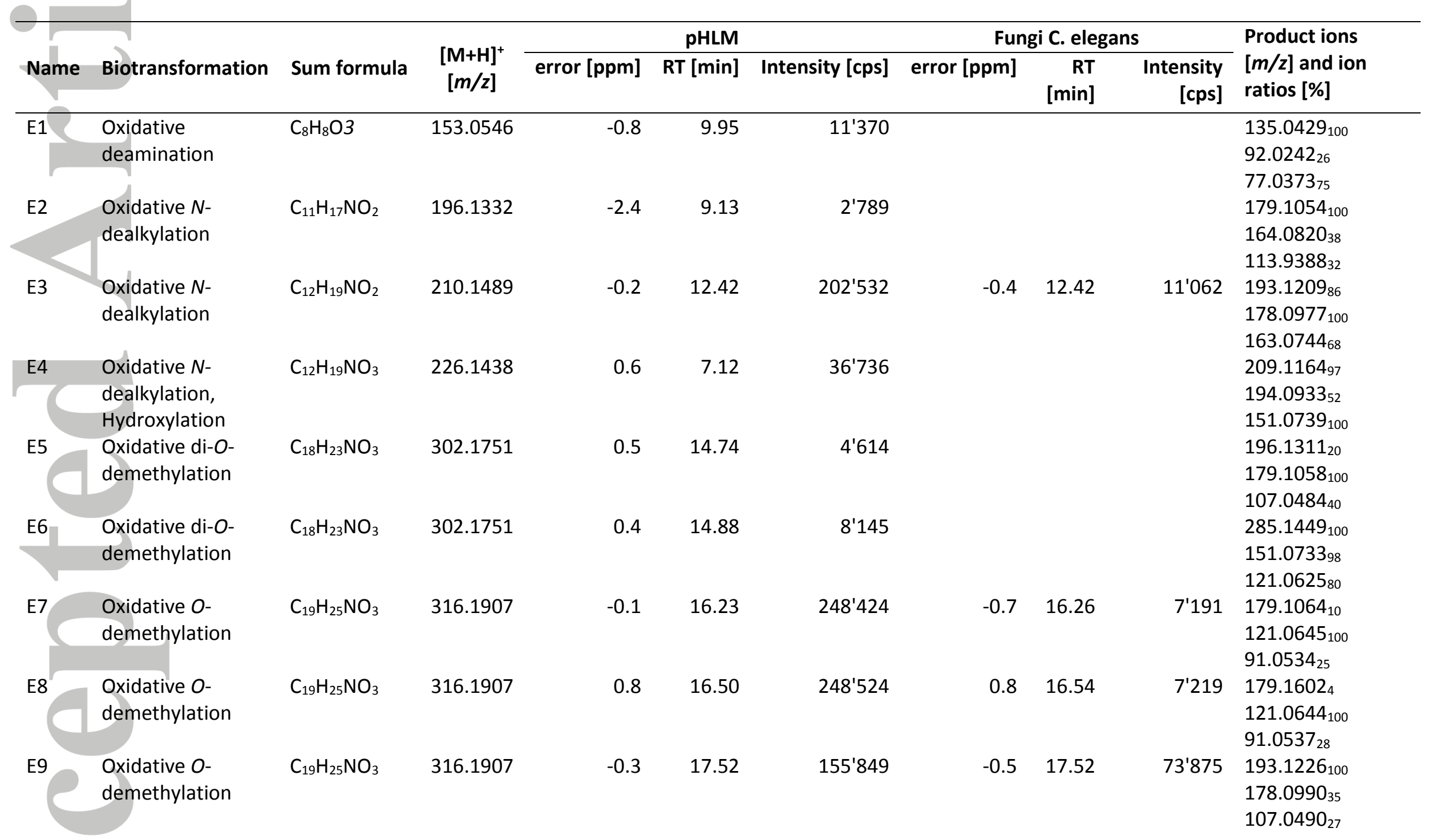

This article is protected by copyright. All rights reserved. 


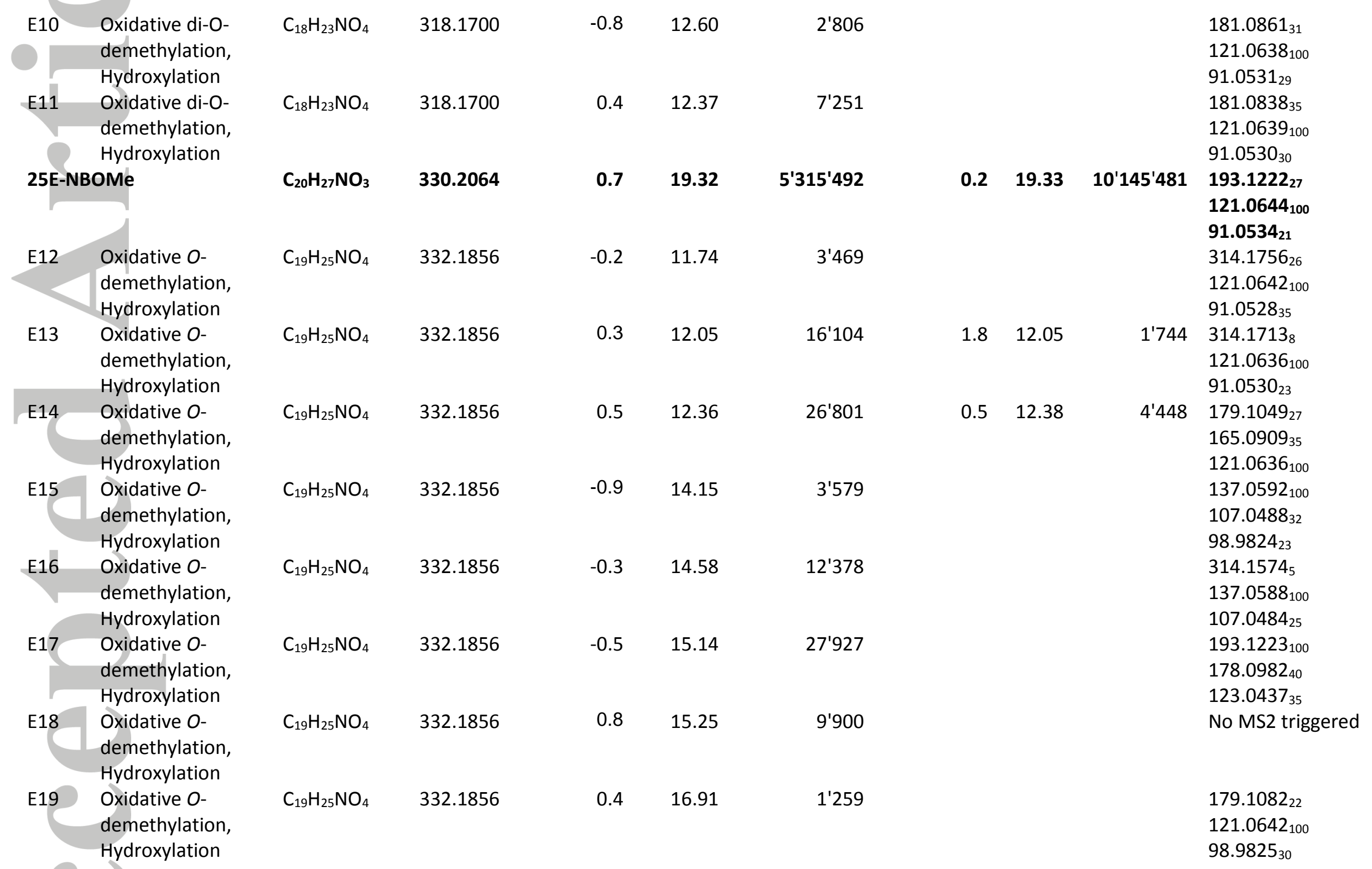

This article is protected by copyright. All rights reserved. 


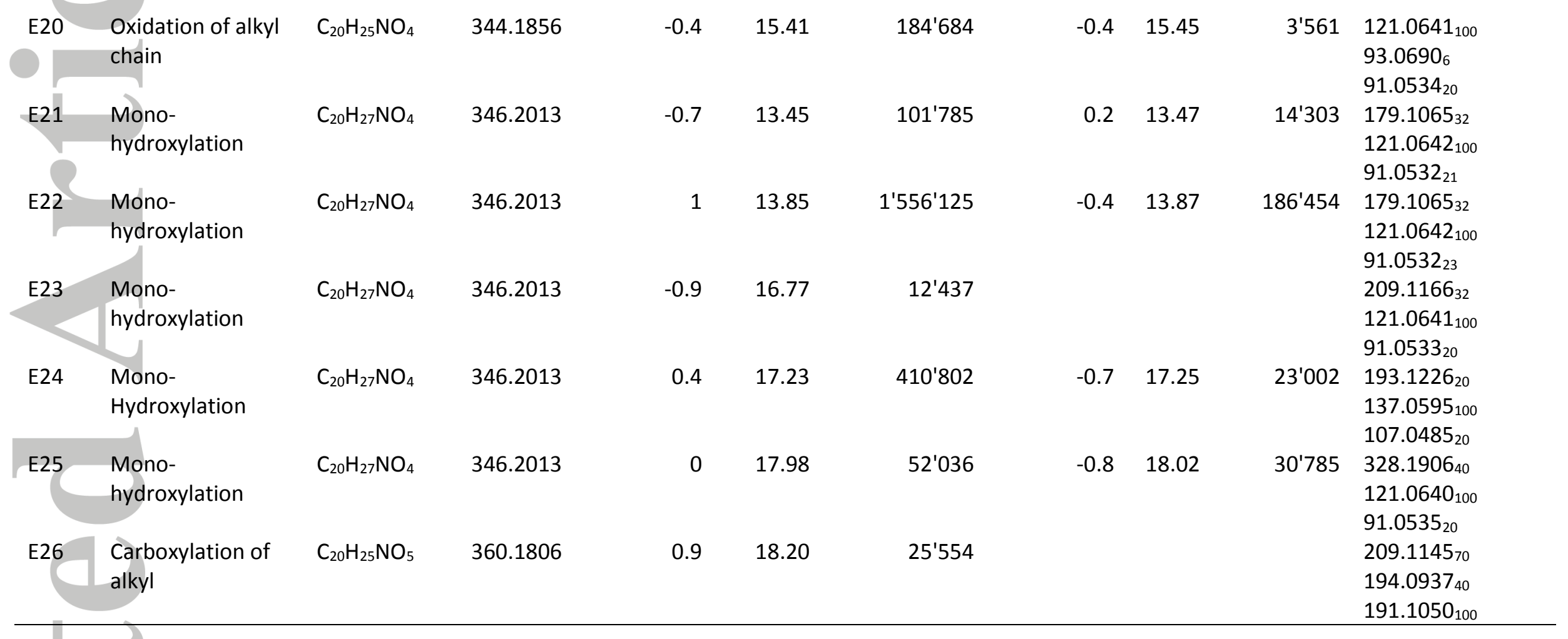


Table 3 Metabolites of 25N-NBOMe identified in pHLM and fungi C. elegans samples sorted by the mass of the protonated molecule [M+H] ${ }^{+}$.

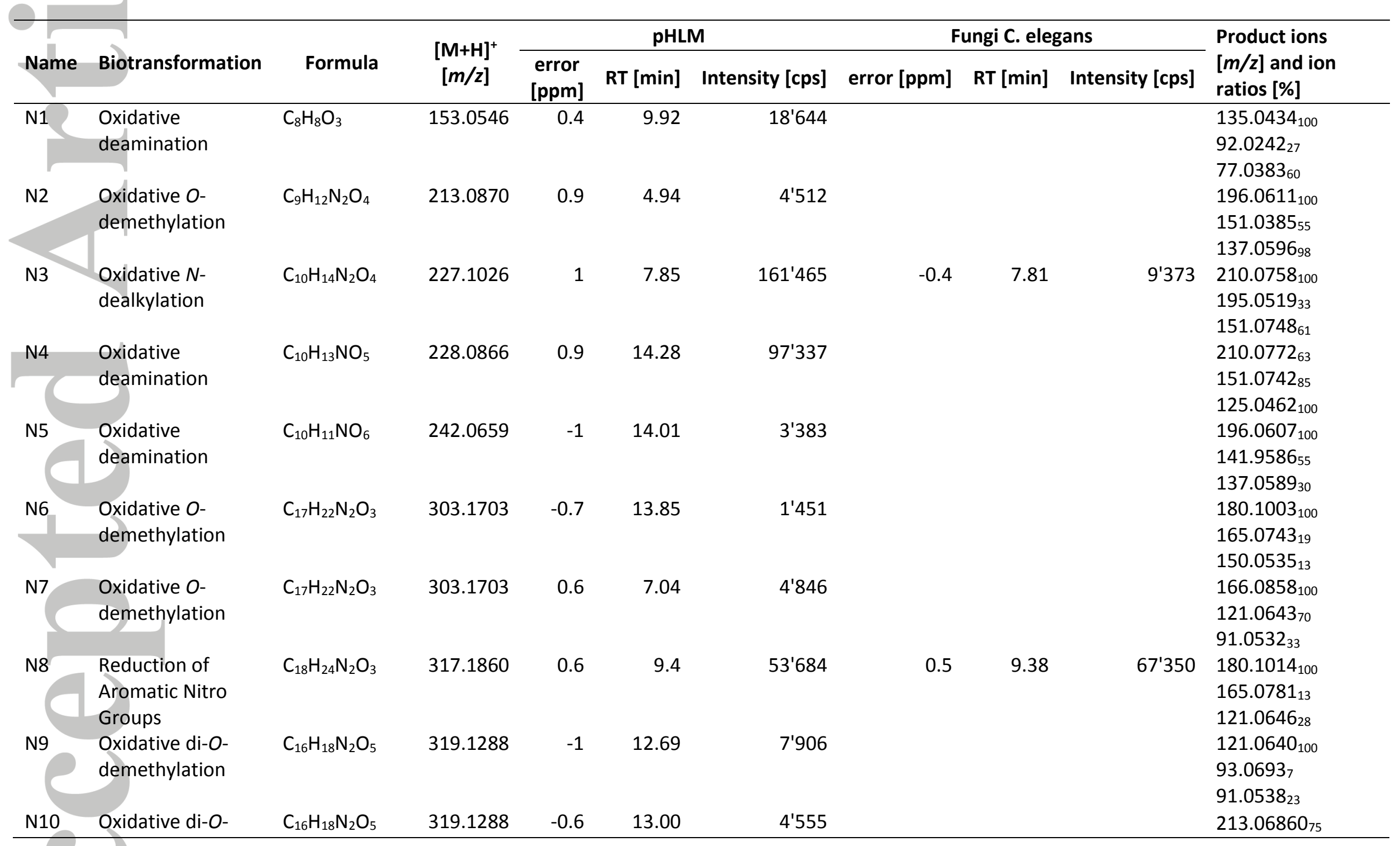

This article is protected by copyright. All rights reserved. 


\begin{tabular}{|c|c|c|c|c|c|c|c|c|c|c|}
\hline \multirow{2}{*}{\multicolumn{2}{|c|}{ demethylation }} & \multirow{4}{*}{$\mathrm{C}_{16} \mathrm{H}_{18} \mathrm{~N}_{2} \mathrm{O}_{5}$} & \multirow{4}{*}{319.1288} & \multirow{4}{*}{-0.3} & \multirow{4}{*}{11.59} & \multirow{4}{*}{ 7'303 } & & & \multirow{2}{*}{\multicolumn{2}{|c|}{$\begin{array}{l}196.0603_{82} \\
107.0483_{100}\end{array}$}} \\
\hline & & & & & & & & & & \\
\hline \multirow{2}{*}{ N11 } & Oxidative di-O- & & & & & & & & & $213.0879_{70}$ \\
\hline & demethylation & & & & & & & & & $196.0588_{65}$ \\
\hline & & & & & & & & & & $107.0486_{100}$ \\
\hline \multirow{3}{*}{ N12 } & Oxidative $O$ - & $\mathrm{C}_{17} \mathrm{H}_{20} \mathrm{~N}_{2} \mathrm{O}_{5}$ & 333.1445 & 0.5 & 14.96 & $68^{\prime} 435$ & -0.7 & 15.02 & 6'454 & $121.0639_{100}$ \\
\hline & demethylation & & & & & & & & & $93.0686_{8}$ \\
\hline & & & & & & & & & & $91.0531_{28}$ \\
\hline \multirow[t]{3}{*}{ N13 } & Oxidative $O$ - & $\mathrm{C}_{17} \mathrm{H}_{20} \mathrm{~N}_{2} \mathrm{O}_{5}$ & 333.1445 & 0.2 & 13.50 & 201'931 & 0.3 & 13.52 & 1'679 & $121.0646_{100}$ \\
\hline & demethylation & & & & & & & & & $93.0698_{6}$ \\
\hline & & & & & & & & & & $91.0532_{25}$ \\
\hline \multirow[t]{3}{*}{ N14 } & Oxidative $O$ - & $\mathrm{C}_{17} \mathrm{H}_{20} \mathrm{~N}_{2} \mathrm{O}_{5}$ & 333.1445 & 0.9 & 13.84 & 230'815 & -0.1 & 13.87 & $32 ' 874$ & $227.1034_{62}$ \\
\hline & demethylation & & & & & & & & & $210.0763_{75}$ \\
\hline & & & & & & & & & & $107.0489_{100}$ \\
\hline \multirow[t]{3}{*}{$25 N-1$} & 3OMe & $\mathrm{C}_{18} \mathrm{H}_{22} \mathrm{~N}_{2} \mathrm{O}_{5}$ & 347.1601 & 1 & 15.73 & 3'773'154 & 0.2 & 15.67 & $13^{\prime} 214 ' 247$ & $121.0642_{100}$ \\
\hline & & & & & & & & & & $93.0609_{15}$ \\
\hline & & & & & & & & & & $91.0534_{30}$ \\
\hline \multirow[t]{3}{*}{ N15 } & Oxidative $O-$ & $\mathrm{C}_{17} \mathrm{H}_{20} \mathrm{~N}_{2} \mathrm{O}_{6}$ & 349.1394 & -0.2 & 12.44 & 4'489 & & & & $227.1043_{53}$ \\
\hline & demethylation, & & & & & & & & & $210.0757_{50}$ \\
\hline & Hydroxylation & & & & & & & & & $123.0438_{100}$ \\
\hline \multirow[t]{3}{*}{ N16 } & Oxidative $O$ - & $\mathrm{C}_{17} \mathrm{H}_{20} \mathrm{~N}_{2} \mathrm{O}_{6}$ & 349.1394 & -0.3 & 13.38 & 2'378 & & & & $272.9789_{8}$ \\
\hline & demethylation, & & & & & & & & & $121.0638_{100}$ \\
\hline & Hydroxylation & & & & & & & & & $91.0540_{25}$ \\
\hline \multirow[t]{3}{*}{ N17 } & Oxidative $O-$ & $\mathrm{C}_{17} \mathrm{H}_{20} \mathrm{~N}_{2} \mathrm{O}_{6}$ & 349.1394 & -0.6 & 11.60 & 2'615 & & & & $272.9863_{8}$ \\
\hline & demethylation, & & & & & & & & & $137.0592_{100}$ \\
\hline & Hydroxylation & & & & & & & & & $107.0487_{21}$ \\
\hline \multirow[t]{3}{*}{ N18 } & Oxidative $O-$ & $\mathrm{C}_{17} \mathrm{H}_{20} \mathrm{~N}_{2} \mathrm{O}_{6}$ & 349.1394 & 0.4 & 11.35 & 29'809 & & & & $227.1021_{60}$ \\
\hline & demethylation, & & & & & & & & & $210.0762_{67}$ \\
\hline & Hydroxylation & & & & & & & & & $123.0434_{100}$ \\
\hline \multirow[t]{3}{*}{ N19 } & $N$-Acethylation of & $\mathrm{C}_{20} \mathrm{H}_{26} \mathrm{~N}_{2} \mathrm{O}_{4}$ & 359.1965 & 0.6 & 12.92 & 4'080 & & & & $222.1125_{40}$ \\
\hline & Primary Aromatic & & & & & & & & & $180.0999_{23}$ \\
\hline & Amine & & & & & & & & & $121.0636_{100}$ \\
\hline N20 & Oxidation of & $\mathrm{C}_{18} \mathrm{H}_{20} \mathrm{~N}_{2} \mathrm{O}_{6}$ & 361.1394 & 0.5 & 13.30 & 3'800 & & & & $239.0675_{5}$ \\
\hline
\end{tabular}

This article is protected by copyright. All rights reserved. 
Secondary Alcohol

\begin{tabular}{|c|c|c|c|c|c|c|c|c|}
\hline & & & & & & & & $\begin{array}{l}121.0638_{100} \\
91.0530_{22}\end{array}$ \\
\hline $\mathrm{C}_{18} \mathrm{H}_{22} \mathrm{~N}_{2} \mathrm{O}_{6}$ & 363.1551 & 0.3 & 17.39 & 5'809 & -0.2 & 17.33 & 1'762 & $\begin{array}{l}121.0644_{100} \\
93.0683_{8} \\
91.0528_{20}\end{array}$ \\
\hline $\mathrm{C}_{18} \mathrm{H}_{22} \mathrm{~N}_{2} \mathrm{O}_{6}$ & 363.1551 & 0.2 & 14.87 & 8'388 & 1.4 & 14.91 & 431 & $\begin{array}{l}345.1416_{5} \\
121.0639_{100} \\
91.0534_{23}\end{array}$ \\
\hline $\mathrm{C}_{18} \mathrm{H}_{22} \mathrm{~N}_{2} \mathrm{O}_{6}$ & 363.1551 & 0.2 & 13.47 & $95^{\prime} 806$ & 0.9 & 13.50 & 3'654 & $\begin{array}{l}137.0595_{85} \\
109.0644_{100} \\
91.0532_{12}\end{array}$ \\
\hline $\mathrm{C}_{18} \mathrm{H}_{22} \mathrm{~N}_{2} \mathrm{O}_{6}$ & 363.1551 & 0 & 13.68 & 283 '892 & -0.2 & 13.71 & 1'878 & $\begin{array}{l}137.0606_{100} \\
109.0673_{30} \\
107.0584_{25}\end{array}$ \\
\hline
\end{tabular}

This article is protected by copyright. All rights reserved. 

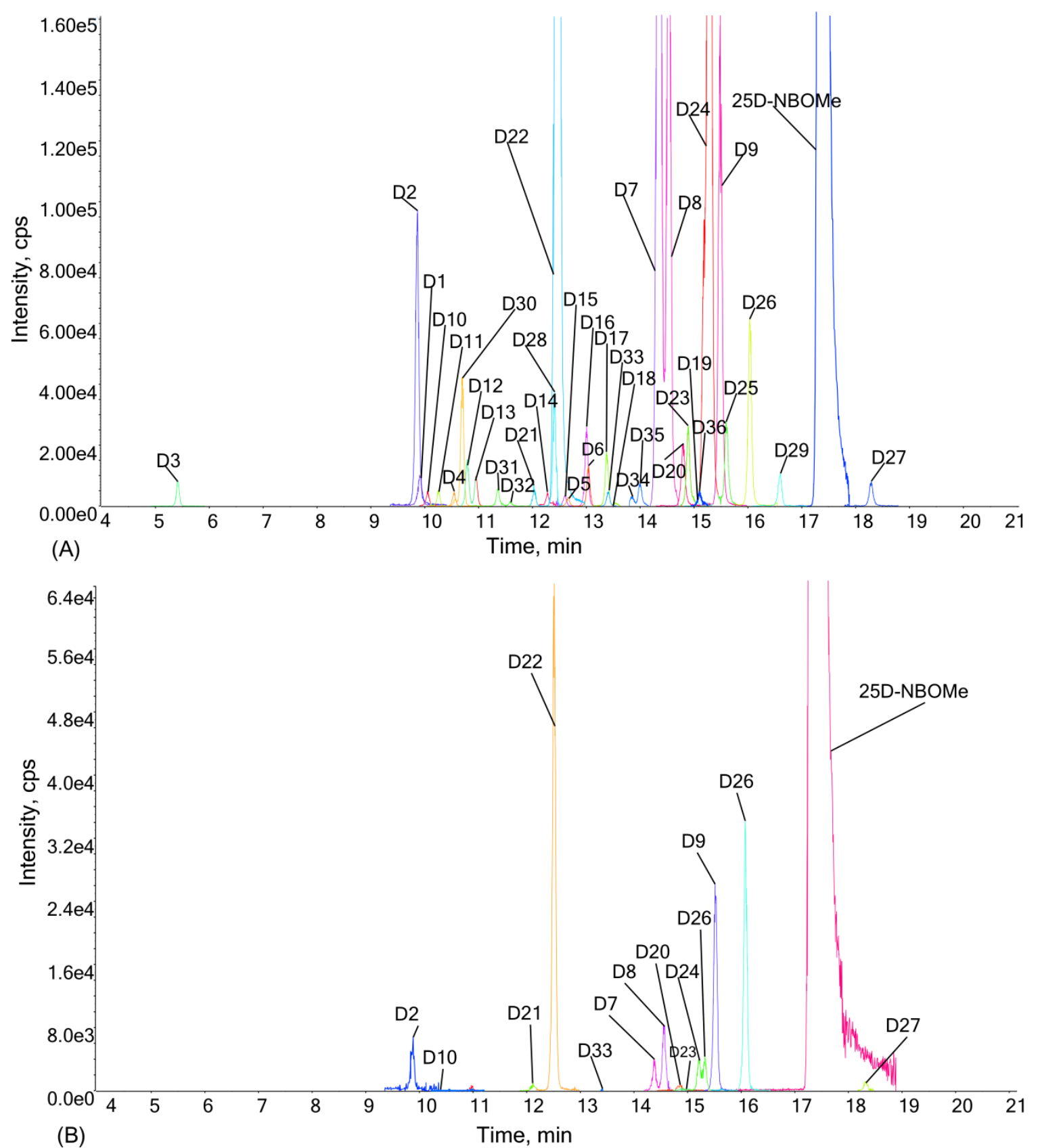

Figure 1: Extracted ion chromatogram of 25D-NBOMe and its metabolites after pHLM incubation with 25D-NBOMe (A). Extracted ion chromatogram of 25D-NBOMe and its metabolites after fungi $C$. elegans incubation with 25D-NBOMe (B). 

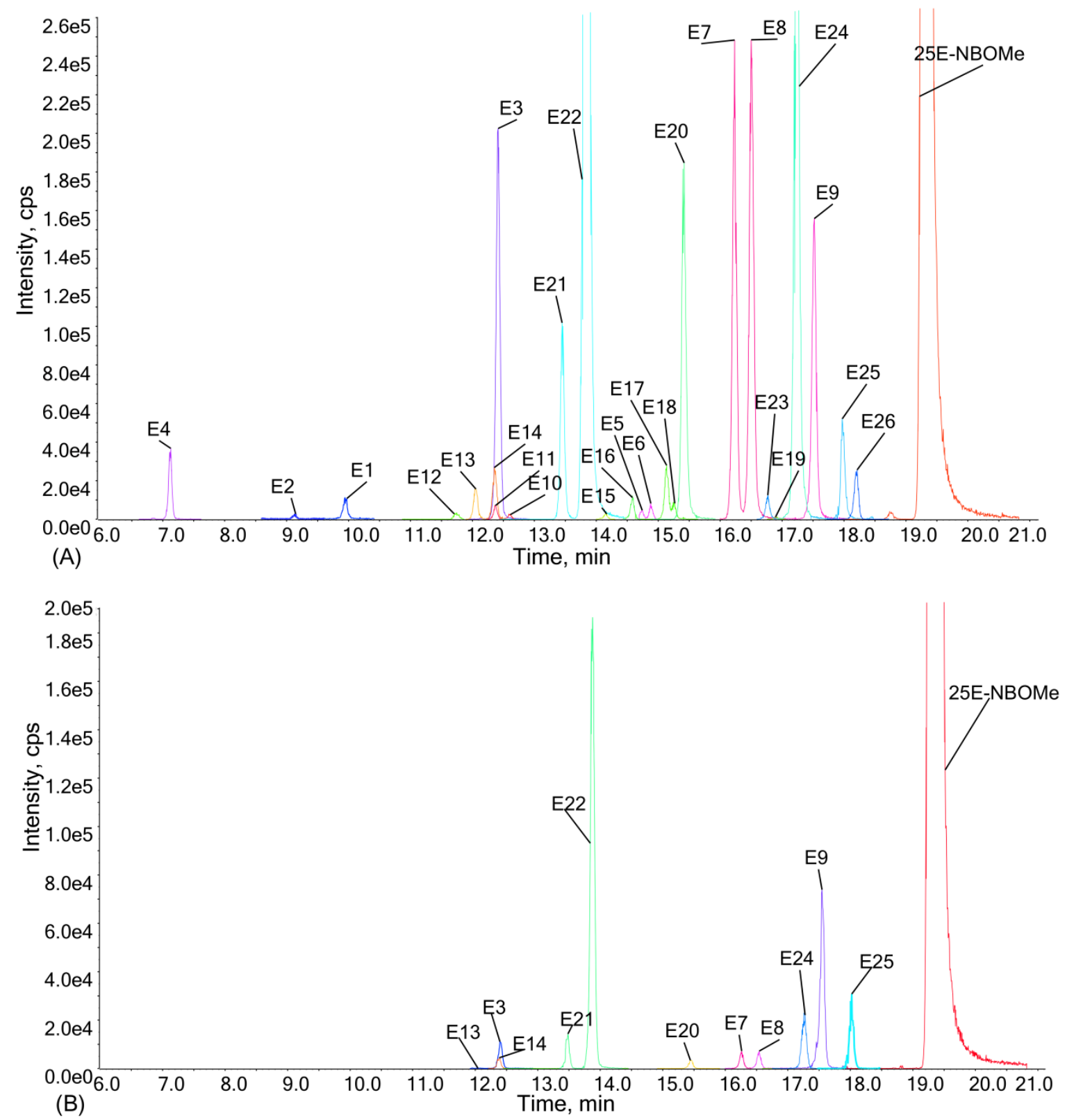

Figure 2 Extracted ion chromatogram of 25-NBOMe and its metabolites after pHLM (2A) and fungi $C$. elegans (2C) incubation with 25E-NBOMe. 

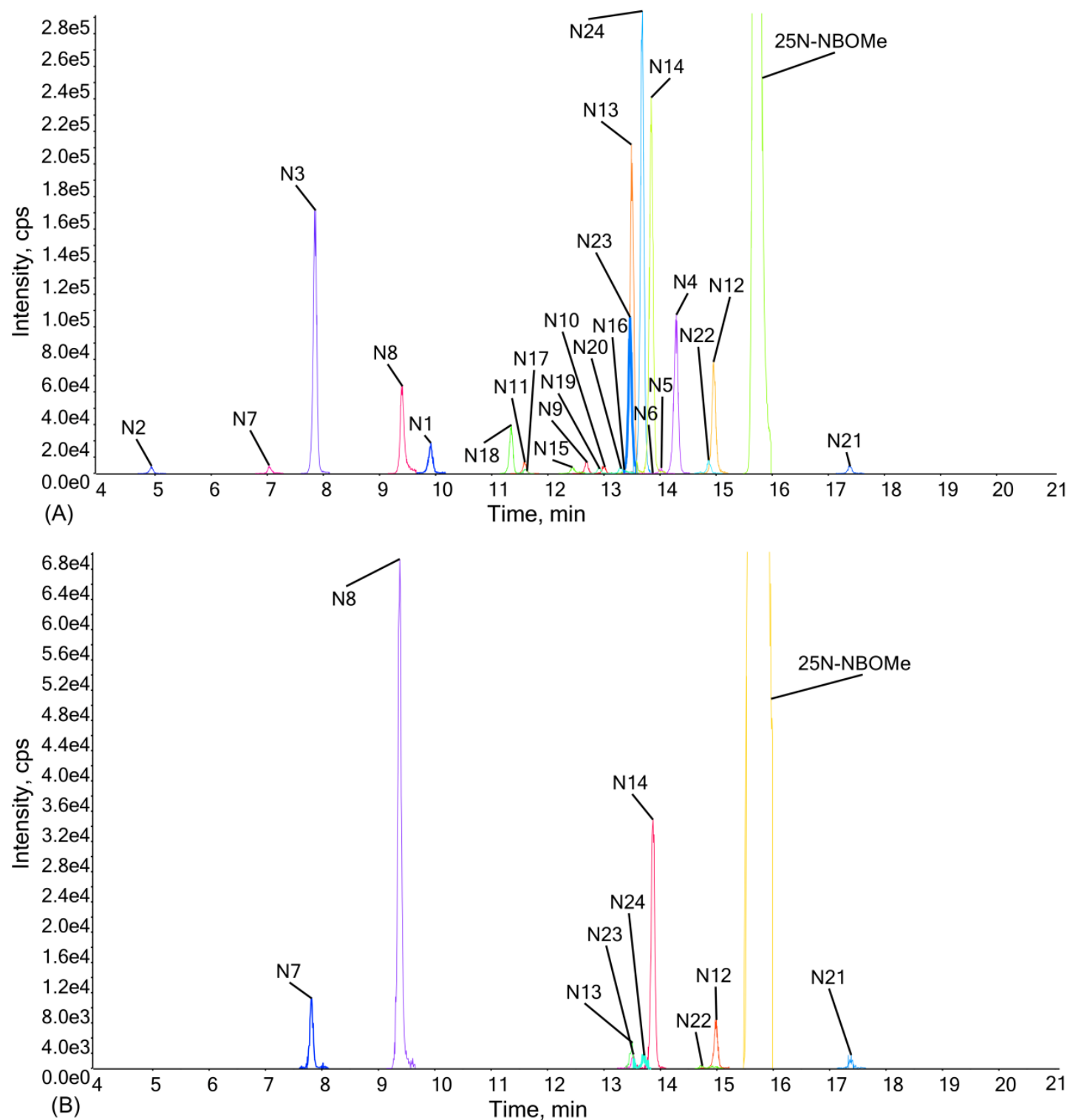

Figure 3 Extracted ion chromatogram of $25 \mathrm{~N}-\mathrm{NBOMe}$ and its metabolites after pHLM (3A) and fungi C. elegans (3B) incubation with $25 \mathrm{~N}-\mathrm{NBOMe}$. For both $\mathrm{pHLM}$ and fungi $\mathrm{C}$. elegans an N-oxide metabolite (N21) eluted after the parent compound. 


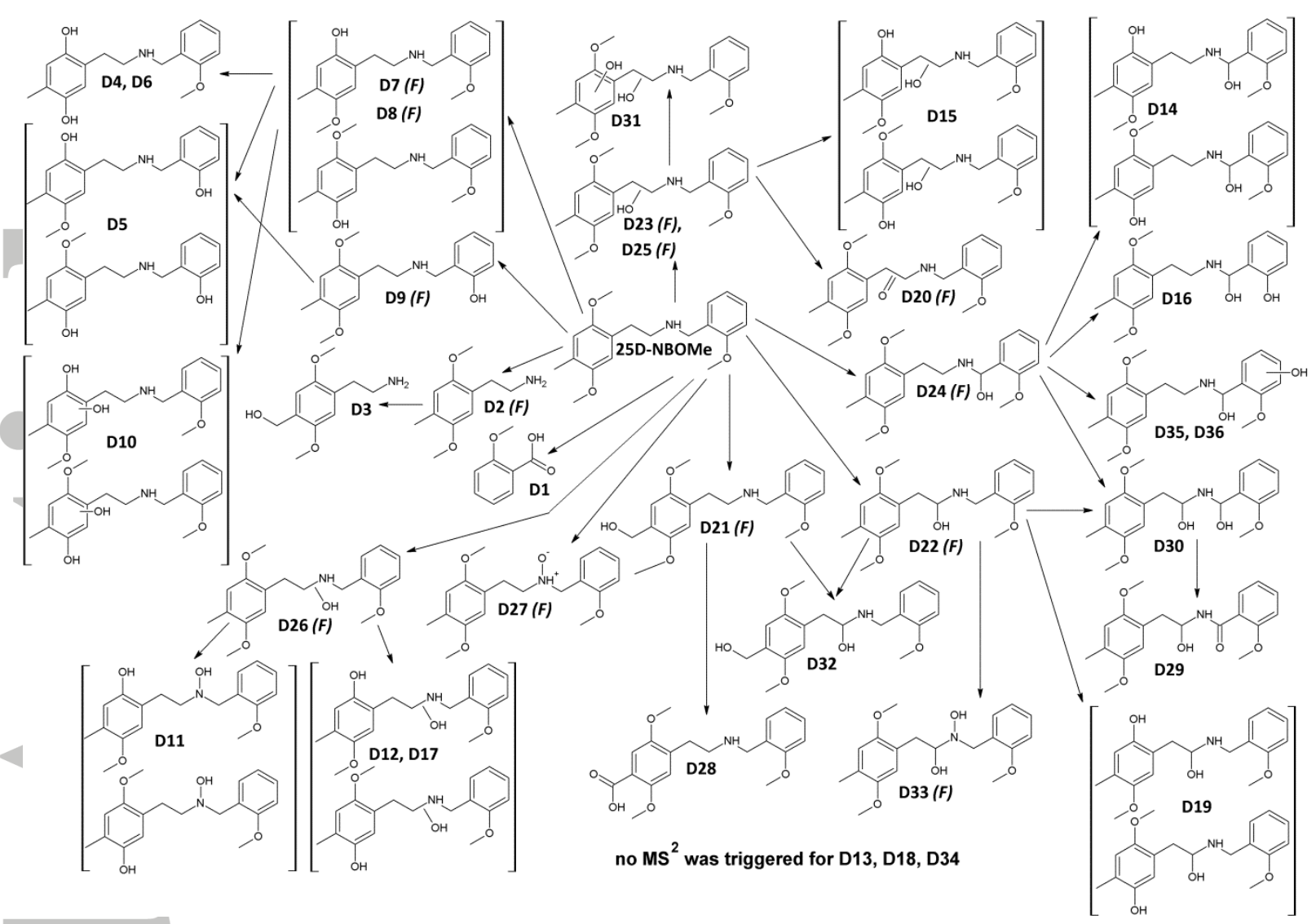

Figure 4 Proposed biotransformation pathway of 25D-NBOMe. Metabolites labelled with (F) were found in both pHLM and fungi $C$. elegans samples. For structures in brackets the exact site of biotransformation could not be determined. 

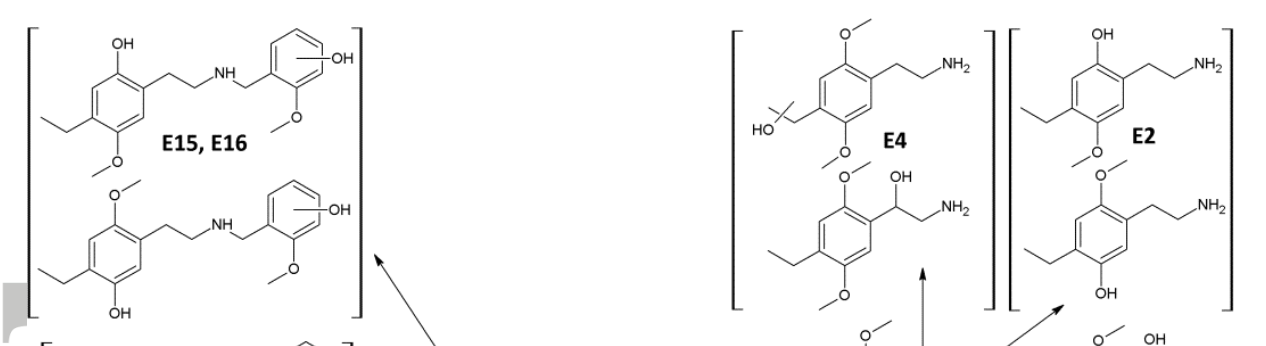

(c)
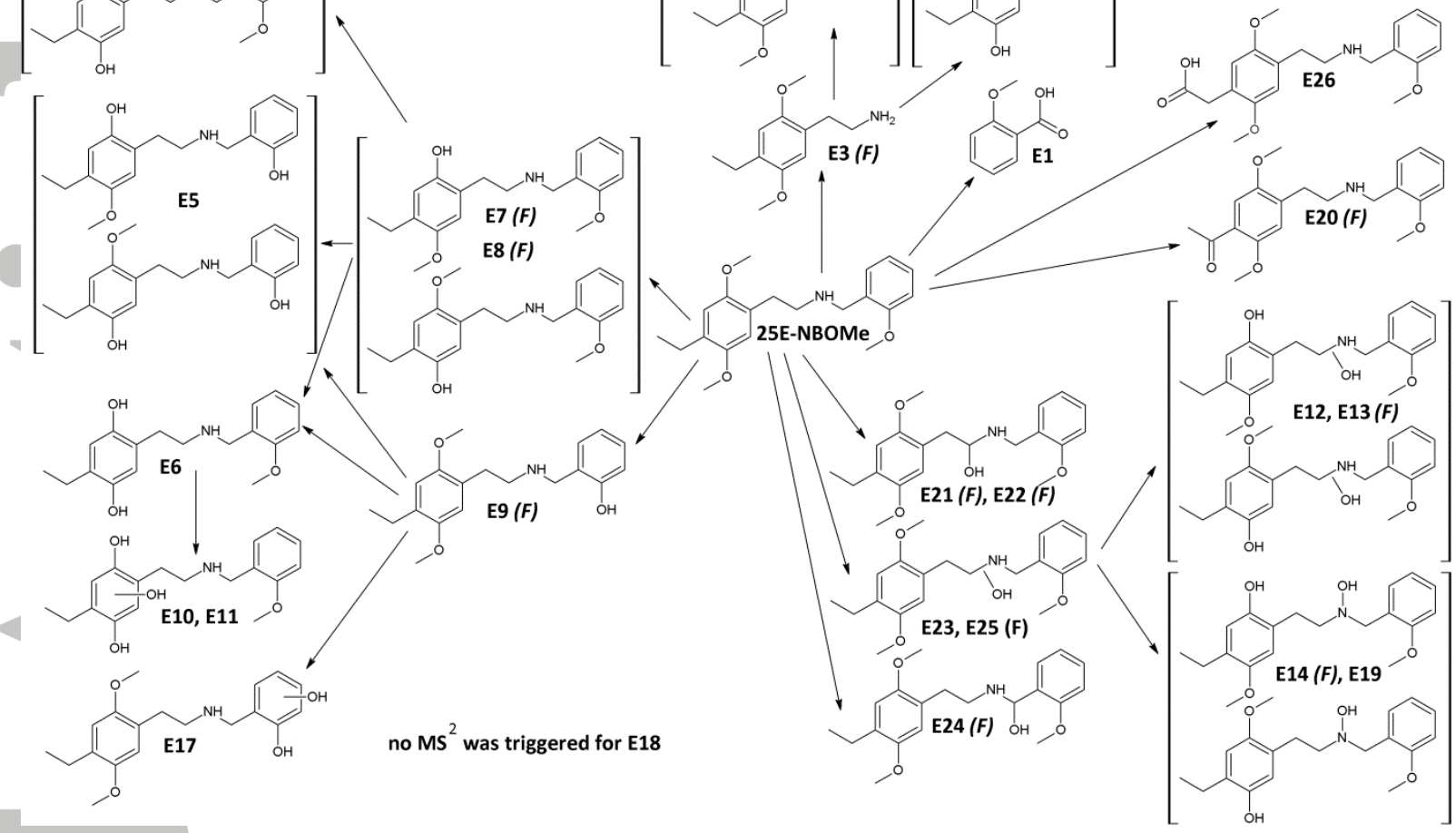

Figure 5 Suggested biotransformation pathway of 25E-NBOMe. Metabolites labelled with (F) were found in both pHLM and fungi $C$. elegans samples. In brackets: exact site of biotransformation could not be determined

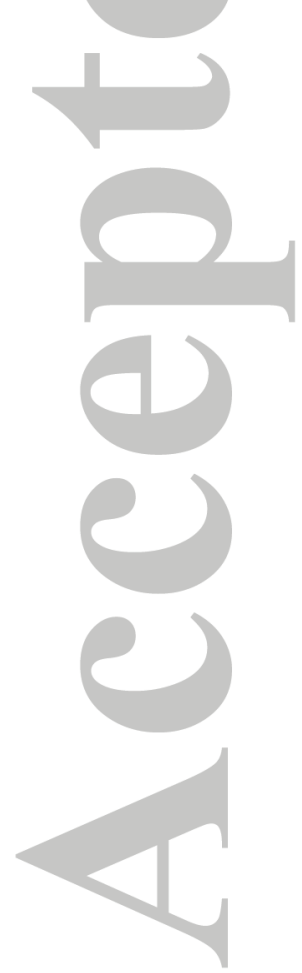




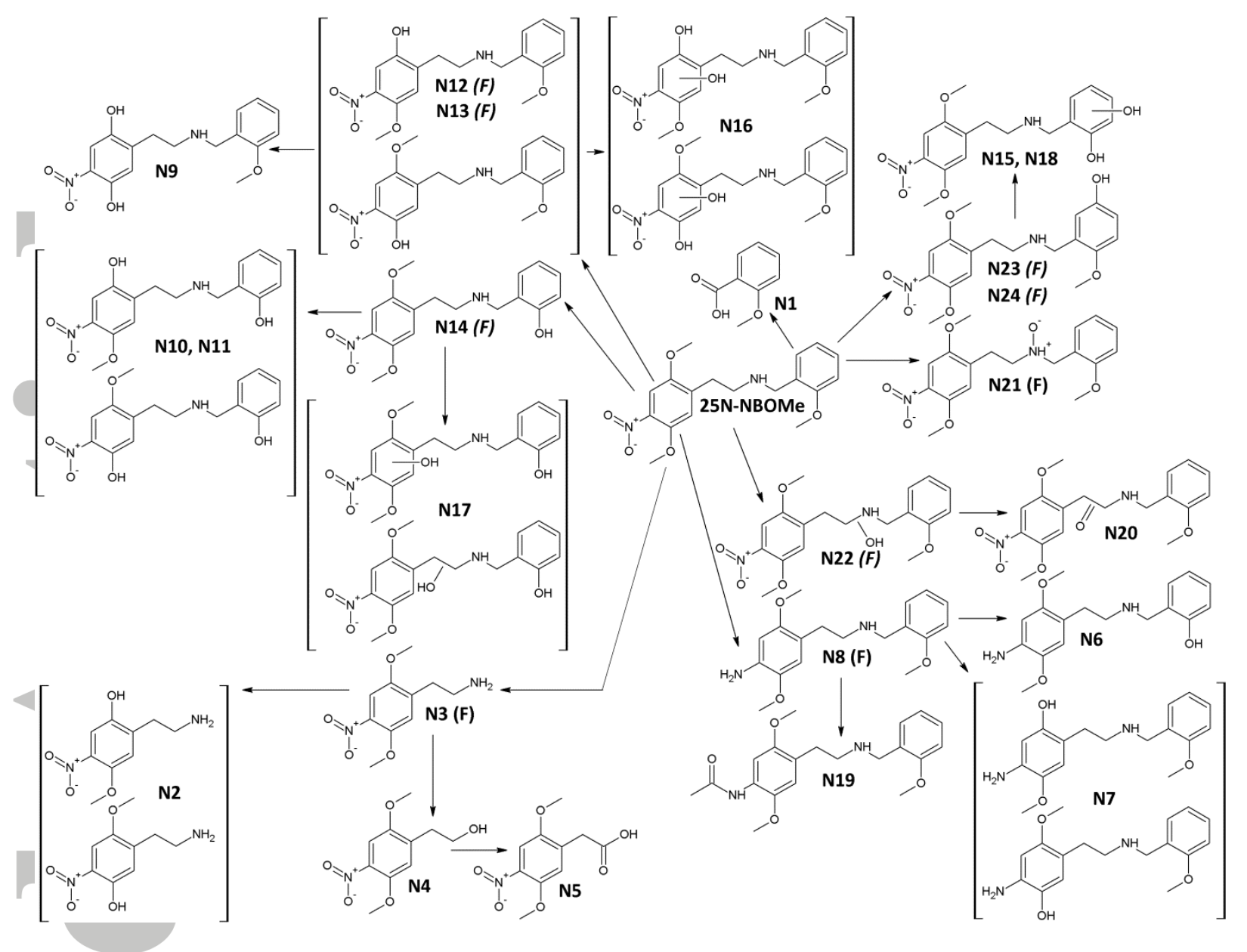

Figure 6 Proposed biotransformation pathway of 25N-NBOMe. Metabolites labelled with (F) were identified in pHLM and fungi $C$. elegans. In brackets: exact site of biotransformation could not be determined.

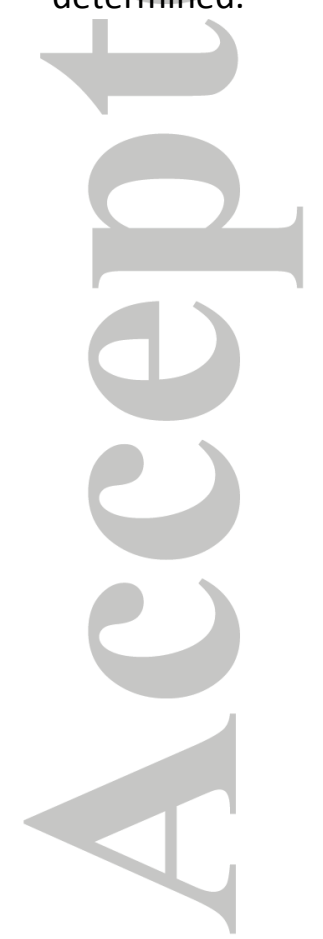



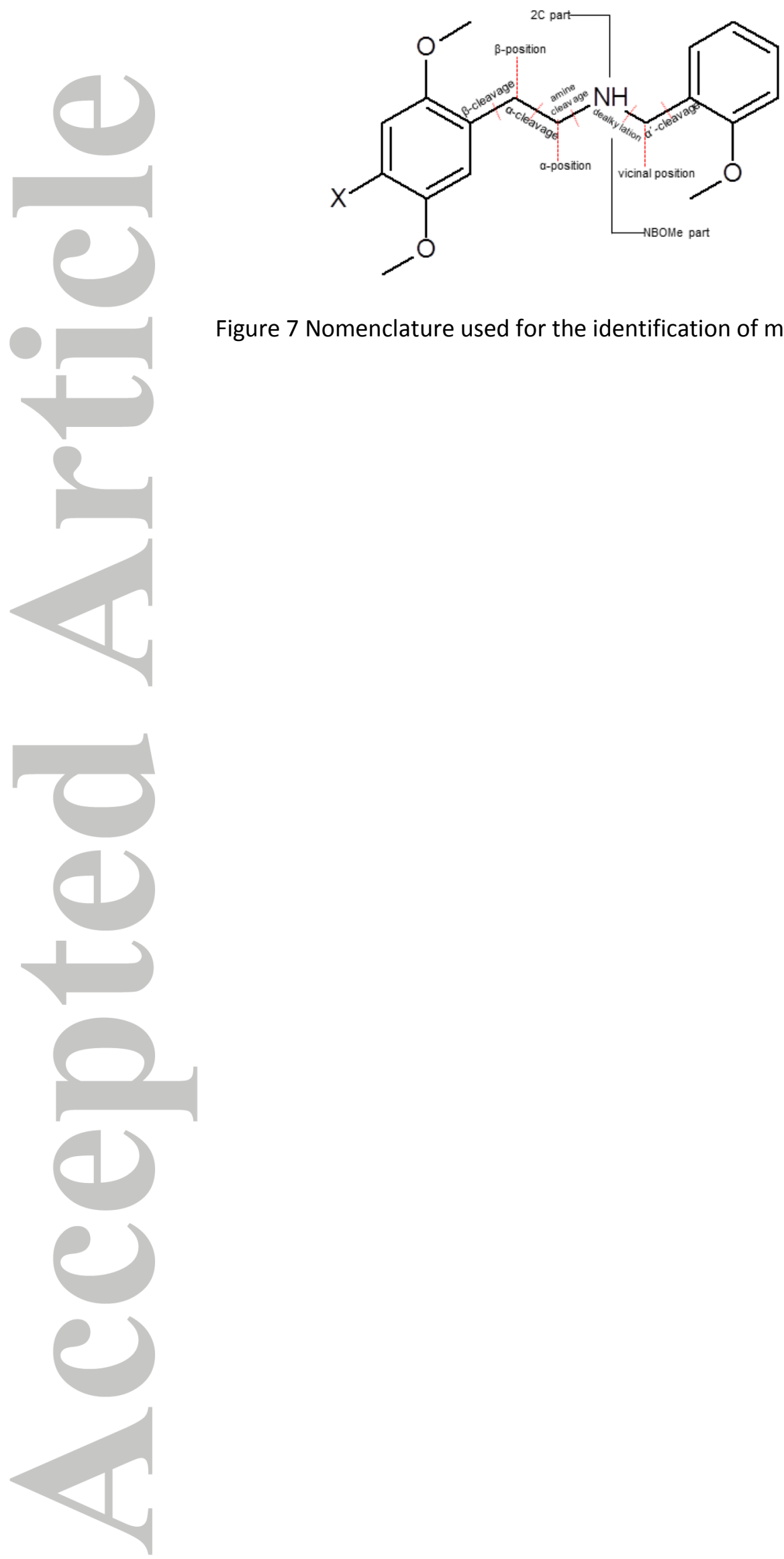

Figure 7 Nomenclature used for the identification of metabolites. 


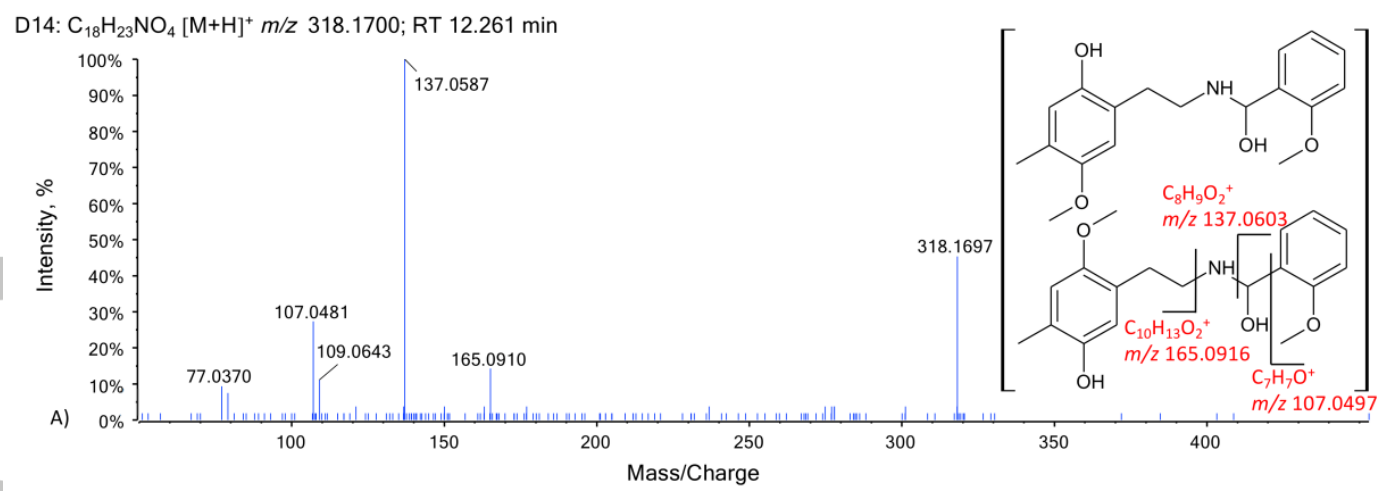

D22: $\mathrm{C}_{19} \mathrm{H}_{25} \mathrm{NO}_{4}[\mathrm{M}+\mathrm{H}]^{+} \mathrm{m} / \mathrm{z}$ 332.1856; RT $12.439 \mathrm{~min}$

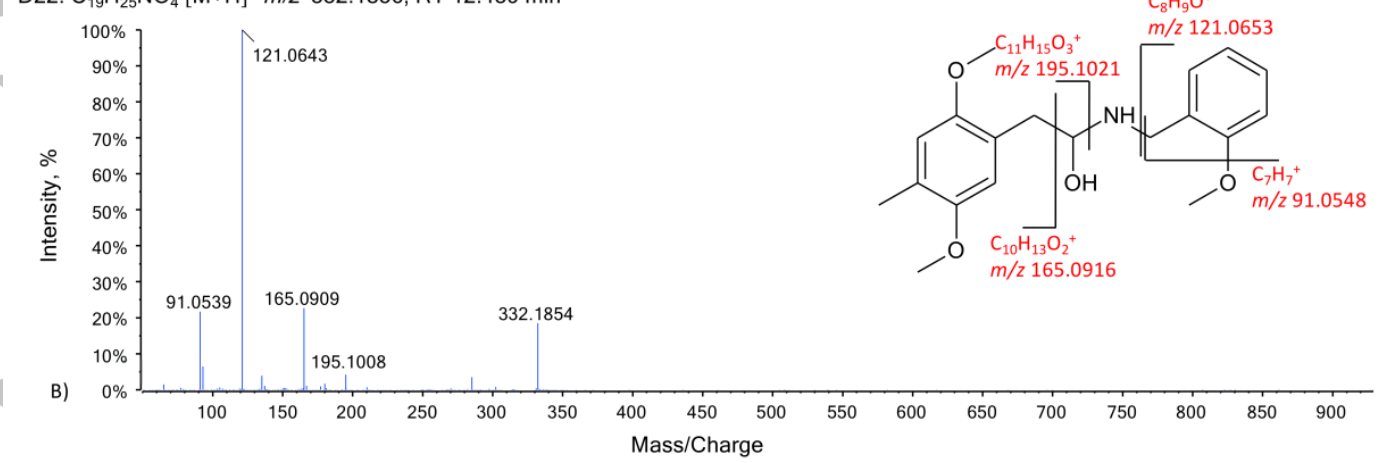

D27: $\mathrm{C}_{19} \mathrm{H}_{25} \mathrm{NO}_{4}[\mathrm{M}+\mathrm{H}]^{+} \mathrm{m} / \mathrm{z}$ 332.1856; RT $18.248 \mathrm{~min}$

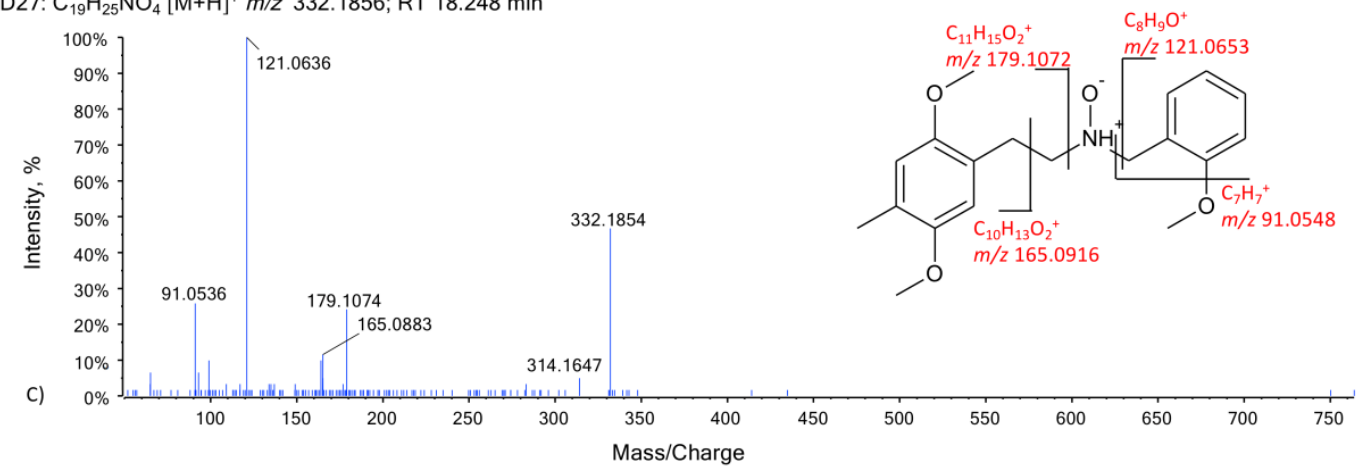

D30: $\mathrm{C}_{19} \mathrm{H}_{25} \mathrm{NO}_{5}[\mathrm{M}+\mathrm{H}]^{+} \mathrm{m} / \mathrm{z}$ 348.1806; RT $10.709 \mathrm{~min}$

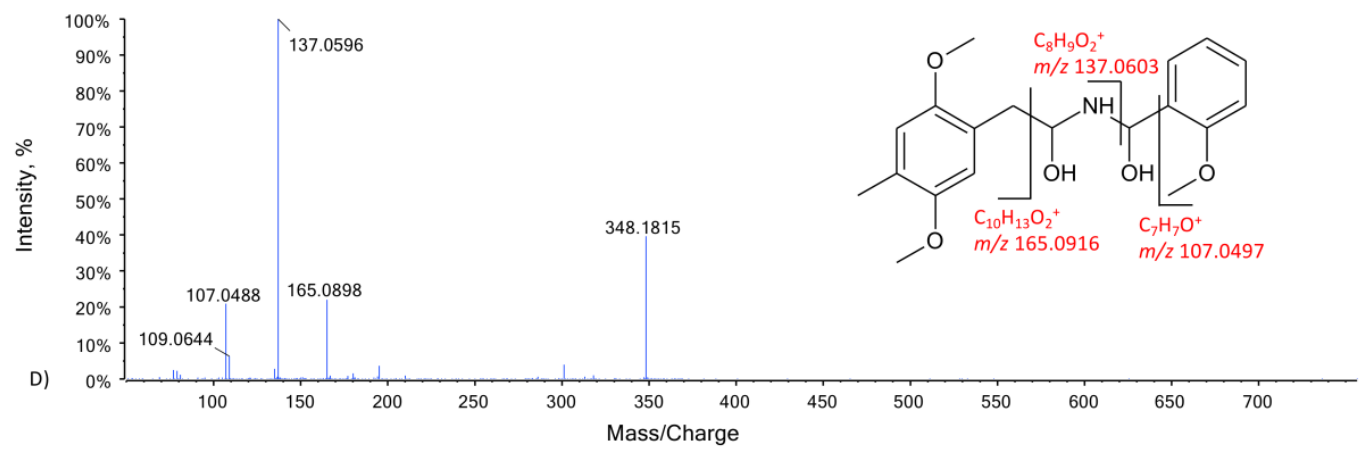


E9: $\mathrm{C}_{19} \mathrm{H}_{25} \mathrm{NO}_{3}[\mathrm{M}+\mathrm{H}]^{+} \mathrm{m} / \mathrm{z}$ 316.1907; RT $17.500 \mathrm{~min}$

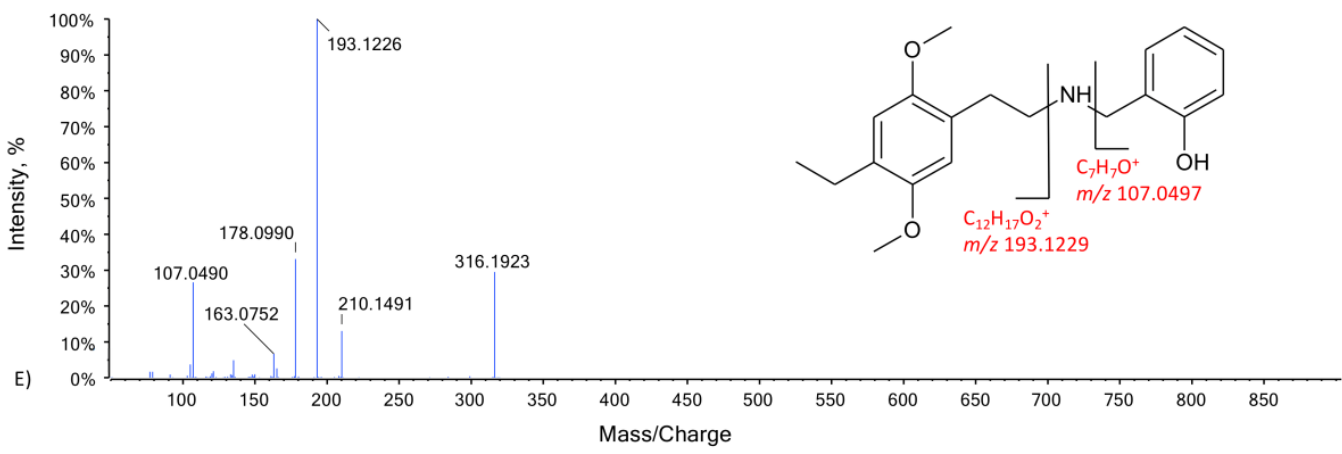

E14: $\mathrm{C}_{19} \mathrm{H}_{25} \mathrm{NO}_{4}[\mathrm{M}+\mathrm{H}]^{+} \mathrm{m} / \mathrm{z} 332.1856 ; 12.340 \mathrm{~min}$

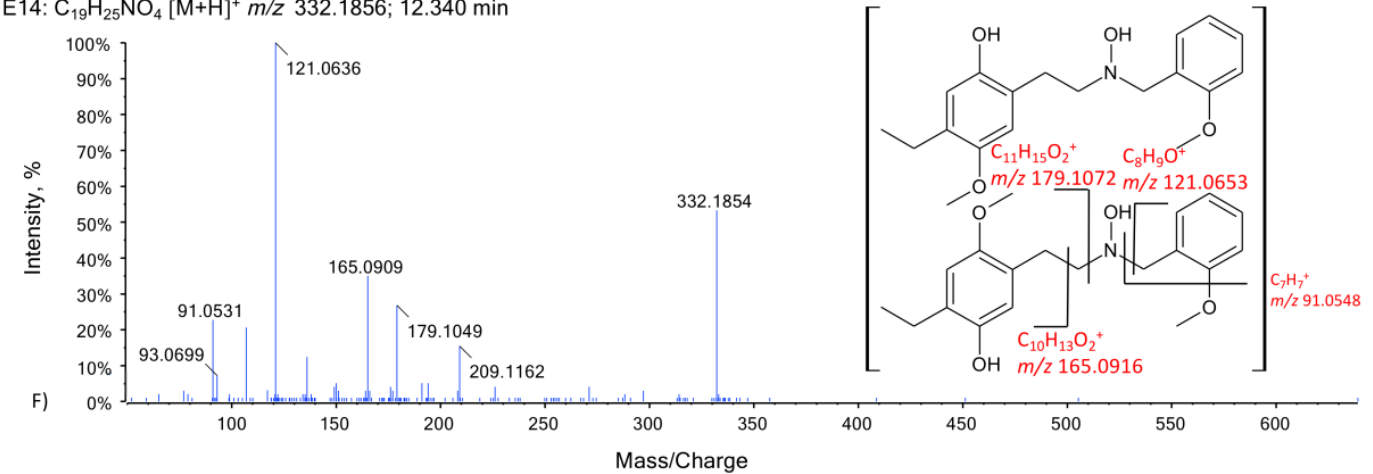

E15: $\mathrm{C}_{19} \mathrm{H}_{25} \mathrm{NO}_{4}[\mathrm{M}+\mathrm{H}]^{+} \mathrm{m} / \mathrm{z} 332.1856 ; 14.142 \mathrm{~min}$

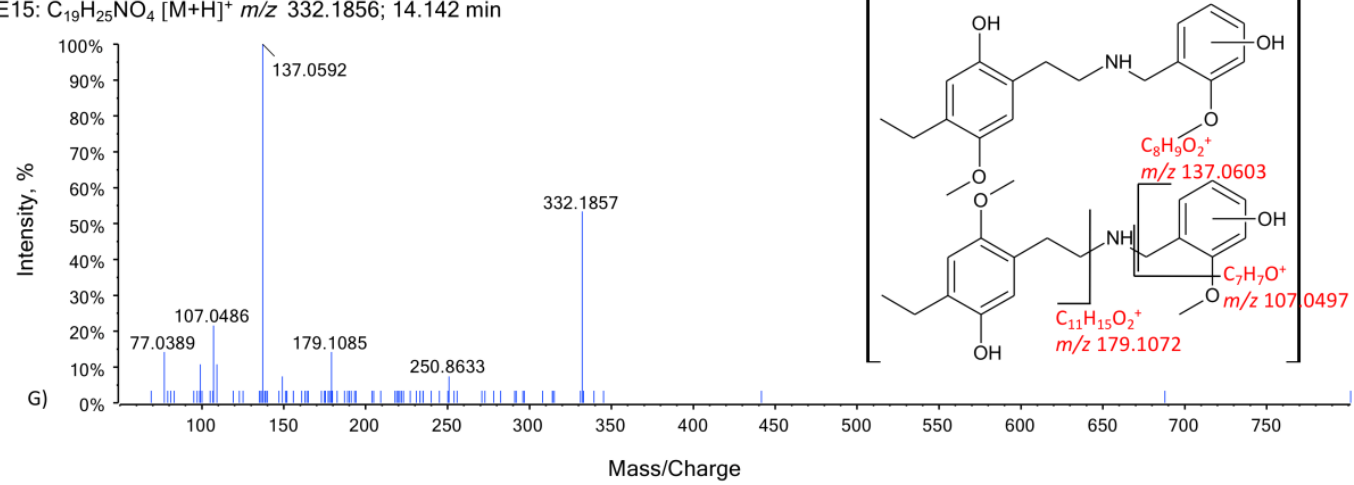

E22: $\mathrm{C}_{20} \mathrm{H}_{27} \mathrm{NO}_{4}[\mathrm{M}+\mathrm{H}]^{+} \mathrm{m} / \mathrm{z}$ 346.2013; RT $13.744 \mathrm{~min}$

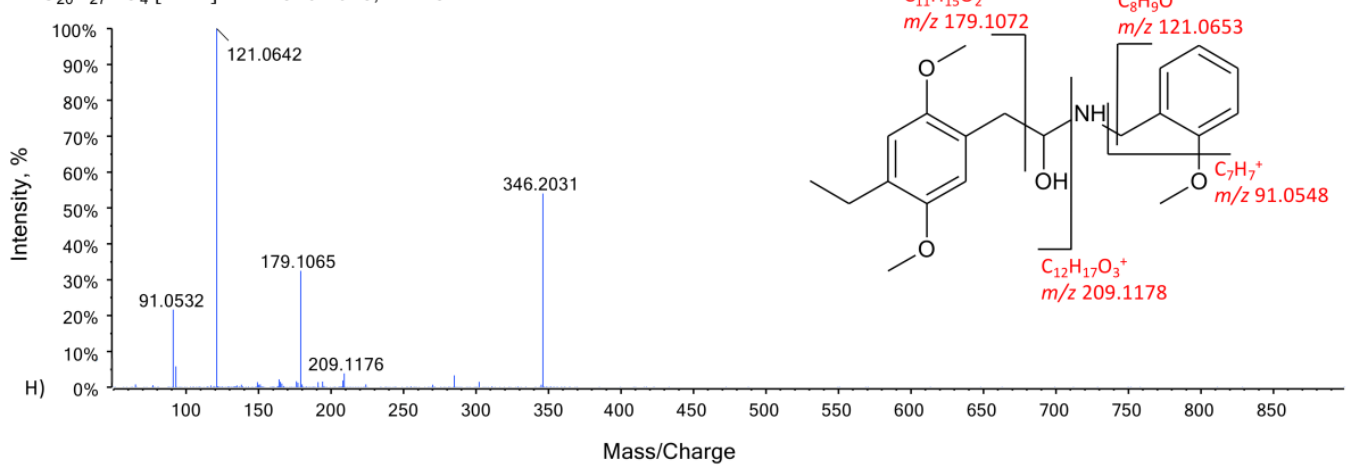




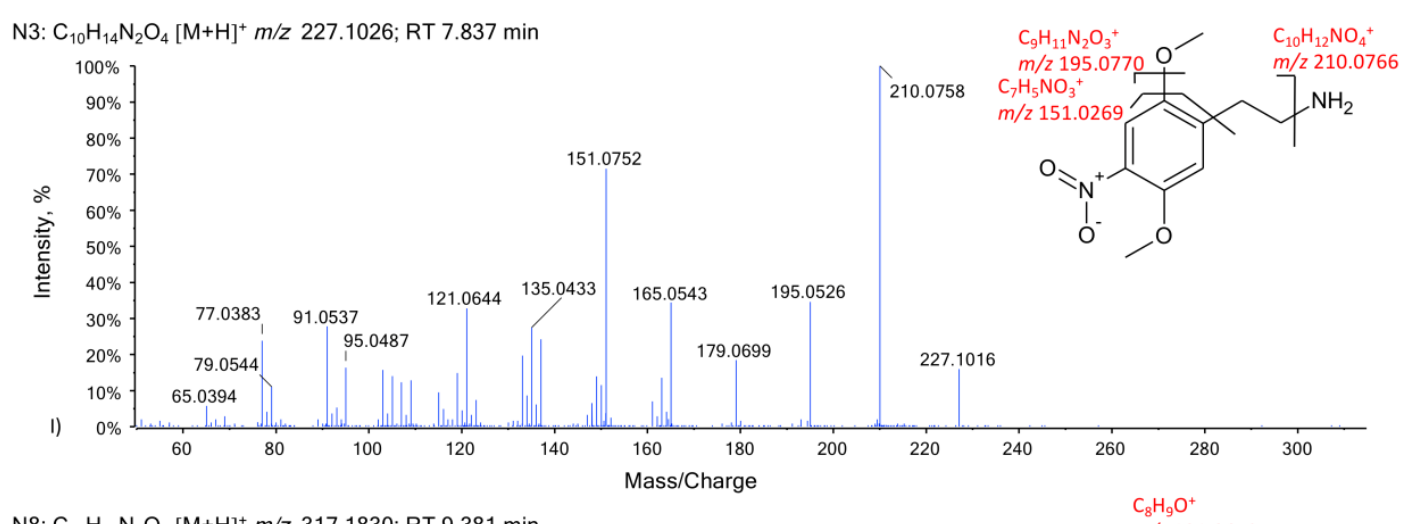

N8: $\mathrm{C}_{18} \mathrm{H}_{24} \mathrm{~N}_{2} \mathrm{O}_{3}[\mathrm{M}+\mathrm{H}]^{+} \mathrm{m} / \mathrm{z}$ 317.1830; RT $9.381 \mathrm{~min}$

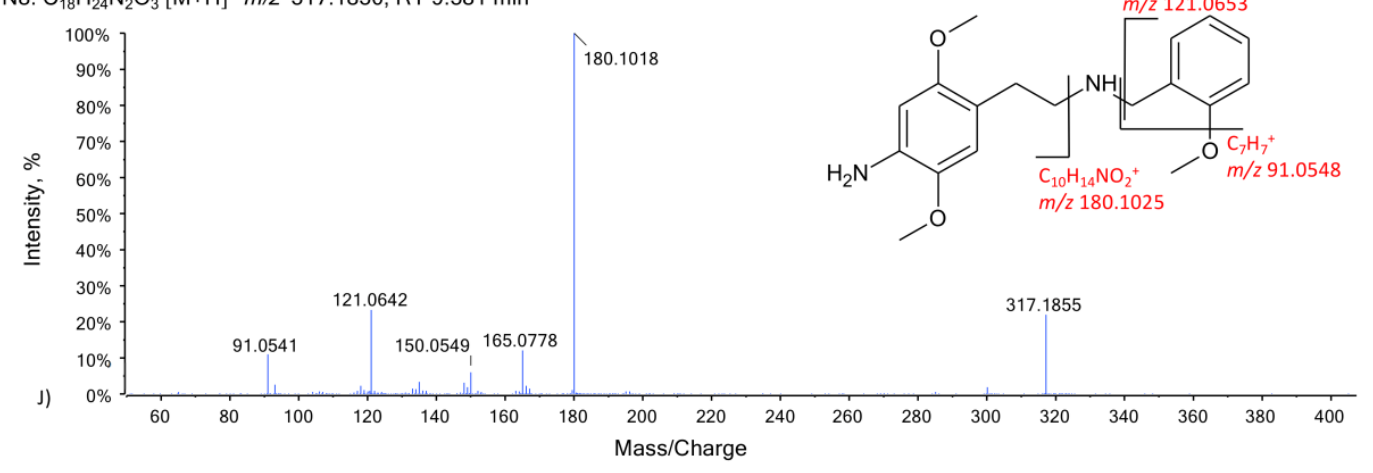

N11: $\mathrm{C}_{16} \mathrm{H}_{18} \mathrm{~N}_{2} \mathrm{O}_{5}[\mathrm{M}+\mathrm{H}]^{+} \mathrm{m} / \mathrm{z} 319.1288 ; \mathrm{RT} 11.599 \mathrm{~min}$

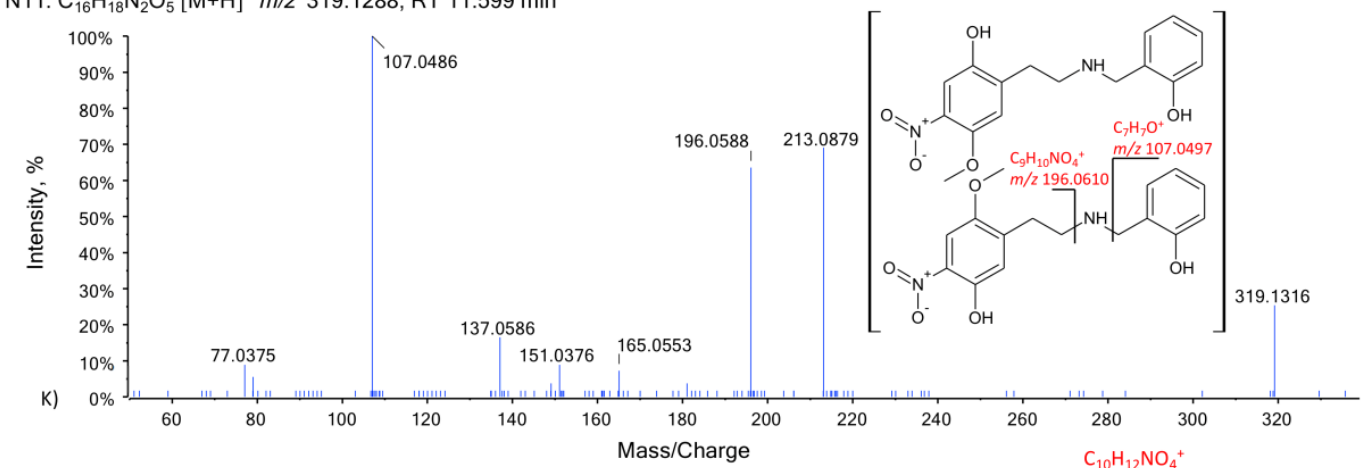

N15: $\mathrm{C}_{17} \mathrm{H}_{20} \mathrm{~N}_{2} \mathrm{O}_{6}[\mathrm{M}+\mathrm{H}]^{+} \mathrm{m} / \mathrm{z} 349.1394 ; \mathrm{RT} 12.424 \mathrm{~min}$

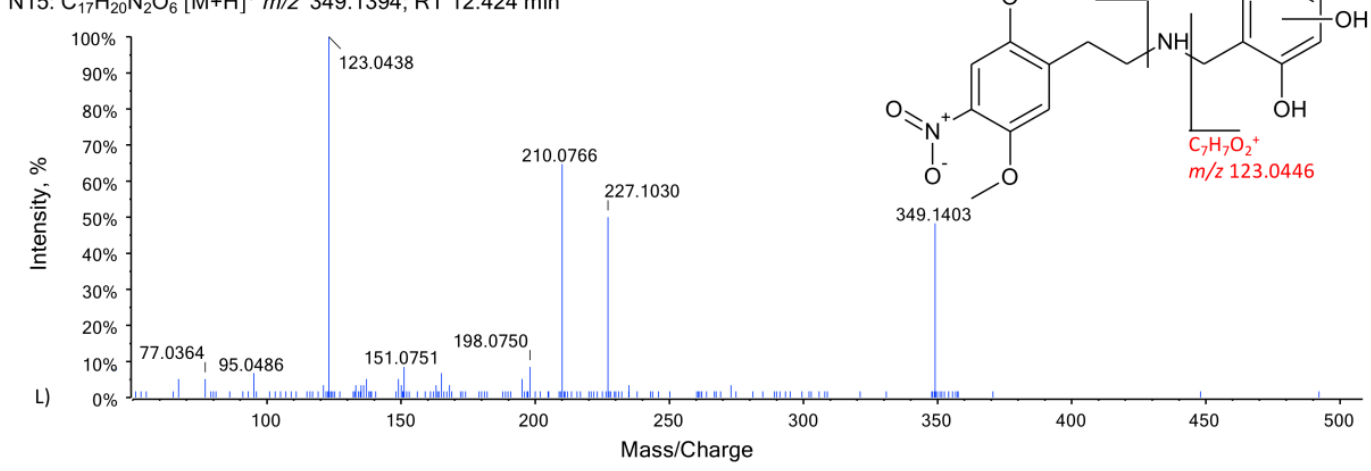

Figure 8 Representative product ion spectra of 25D-NBOMe (A, B, C, D), 25E-NBOMe (E, F, G, H) and $25 \mathrm{~N}-\mathrm{NBOMe}(\mathrm{I}, \mathrm{J}, \mathrm{K})$ metabolites after incubation in pHLM and fungi $\mathrm{C}$. elegans. Fragmentation was selected for the ten most abundant precursor ions with CE of $35 \mathrm{eV}$ with a CES of $\pm 15 \mathrm{eV}$. 
In vitro phase I metabolism of three phenethylamines 25D-NBOMe, 25E-NBOMe and 25NNBOMe using microsomal and microbial models

Katharina Elisabeth Grafinger, Katja Stahl, Andreas Wilke, Stefan König , Wolfgang Weinmann

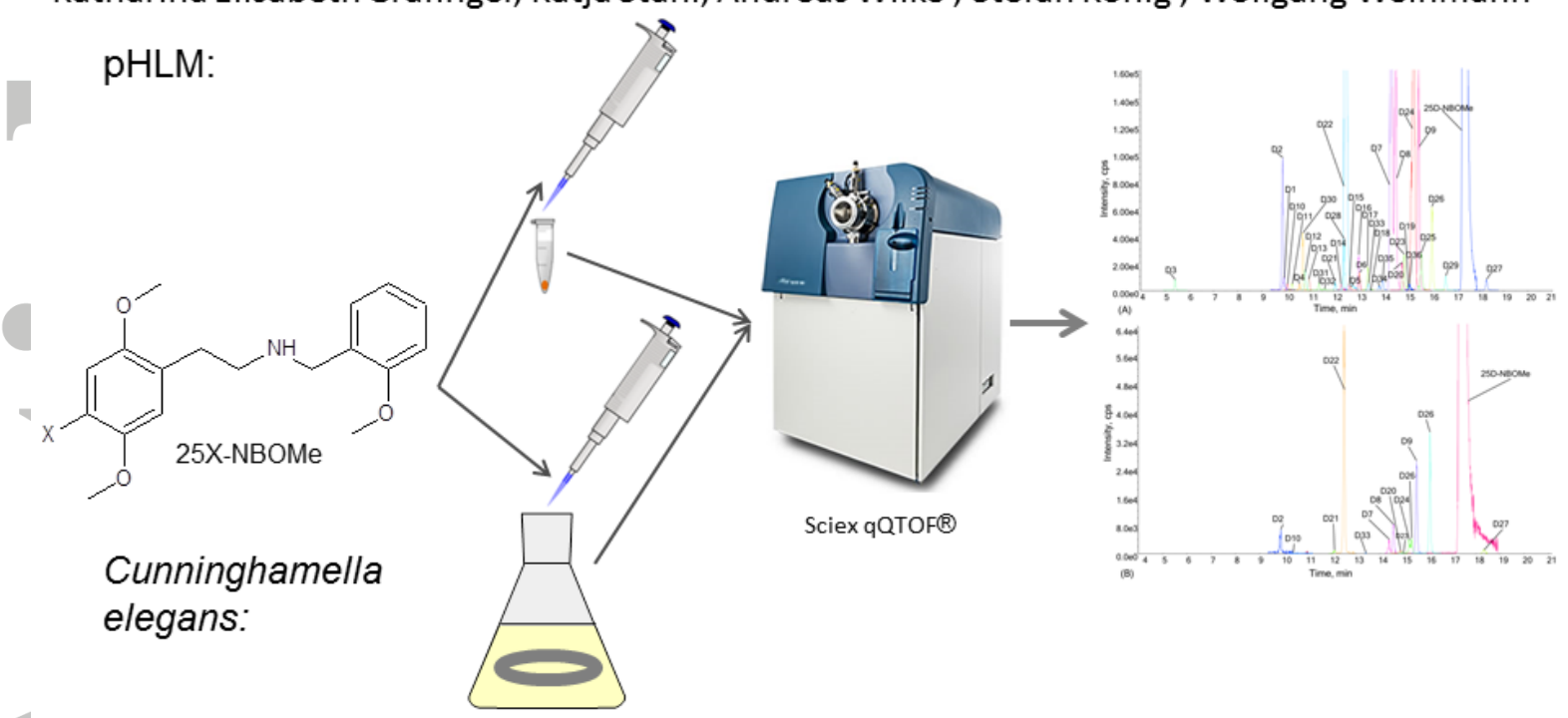

Results of the microsomal pHLM and microbial fungi $C$. elegans experiments, analysed with LCHR-MS/MS identified 36 25D-NBOMe, 26 25E-NBOMe and 24 25N-NBOMe phase I metabolites. $\mathrm{N}$-oxides and hydroxylamine metabolites were reported for 25X-NBOMes for the first time and unique $25 \mathrm{~N}-\mathrm{NBOMe}$ metabolites identified. 